\title{
Caracterización de las tramas urbanas de la ciudad de Manizales, Colombia (1849-2017)
}

Characterization of urban morphology of the city of Manizales, Colombia (1849-2017)

\section{Tania Giraldo-Ospina}

Universidad Nacional de Colombia, sede Manizales (Colombia)

Facultad de Ingeniería y Arquitectura.

\section{Luis-Ricardo Vásquez-Varela}

Universidad Nacional de Colombia, sede Manizales (Colombia)

Facultad de Ingeniería y Arquitectura.

Giraldo-0spina, T., \& Vásquez-Varela, L. R. (2020). Caracterización de las tramas urbanas de la ciudad de Manizales, Colombia (18492017). Revista de Arquitectura (Bogotá), 22(I). 30-43. https://doi. org/10.14718/RevArq.2020.2669

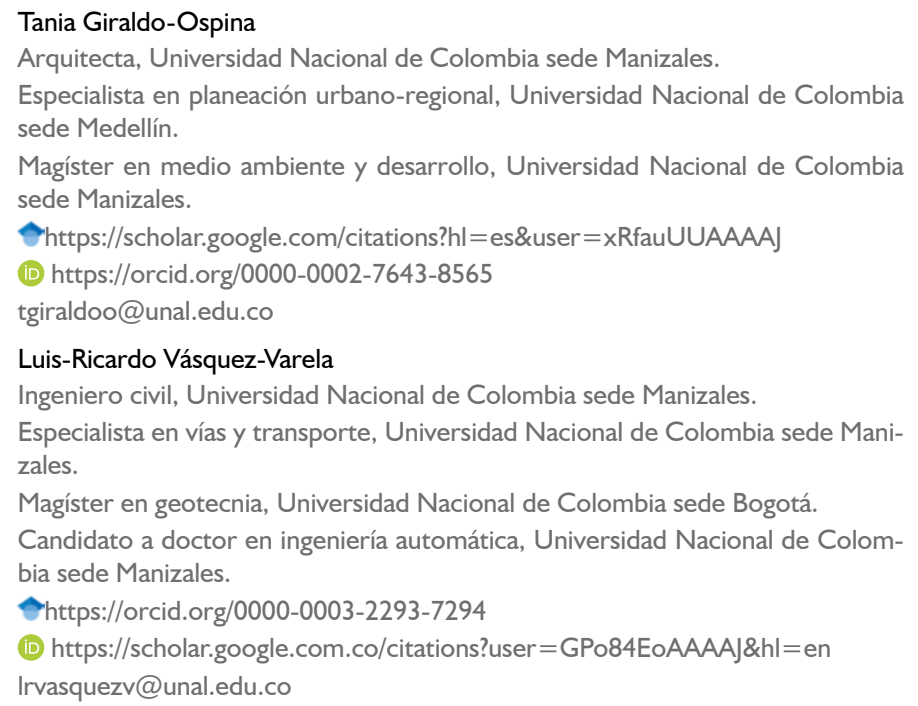

\section{Resumen}

Las investigaciones sobre la evolución morfológica de las ciudades colombianas se concentran en ciudades fundadas durante la época colonial española. El objetivo de la presente investigación fue caracterizar las formas urbanas y su relación con los espacios públicos, a partir de la topografía, la transformación ambiental, los procesos de gestión urbana y los desarrollos urbanísticos entre 1849 y 2017. Mediante el uso de un sistema de información geográfica (SIG), se hizo el análisis de superposición de capas, así como el mapa de pendientes y la caracterización de laderas. Se seleccionaron 24 barrios de los II 4 que tiene en total Manizales. Como resultado se identificaron 8 tipologías de tramas urbanas, diferenciadas en 5 fases de crecimiento urbano. La trama de damero y los grandes movimientos de tierra se dejaron de emplear desde mediados del siglo XX. Las tramas posteriores tratan de adaptarse a las laderas con menos modificación del terreno, pero sin reducir el riesgo geotécnico. En cuanto al espacio público, muchas de las zonas verdes son laderas con espacios residuales que no cuentan con diseño de espacio público y no permiten el uso recreativo, al contrario de áreas localizadas en topografías planas, que favorecen el uso recreativo y sin tratamientos geotécnicos.

Palabras clave: desarrollo urbano; ecología urbana; espacio público; gestión del riesgo; morfología urbana; ordenamiento territorial; sistema de información geográfica (SIG); transformación ambiental

\section{Abstract}

Research on the morphological evolution of Colombian cities has focused on cities established in the Spanish colonial era. This article addresses the characterization of urban forms in Manizales and their relationship with urban spaces as of the topography, environmental transformation, urban management processes and urban development between 1849 and 2017. Through the use of a Geographic Information System (GIS), an analysis of layer overlay was carried out, as well as a slope map and a slope characterization. Twenty-four out of the II 4 neighborhoods of the city were selected, identifying eight typologies of urban networks differentiated in five phases of urban growth. The checkerboard plot and the significant earthwork were discontinued since the mid-twentieth century. Subsequent urban networks try to adapt to the slopes with less terrain modification but without a reduction of the geotechnical risk. As for the public space, many of the green areas are slopes with residual spaces that do not have a public space design and do not allow recreational use, unlike areas located on flat topographies, which favor recreational use without geotechnical treatments. This interdisciplinary research becomes relevant for urban management insofar as no studies were found that integrate urban networks with slope characterization.
\end{abstract}

Keywords: urban development; urban ecology; public space; risk management; urban morphology; territorial ordering; geographic information system (GIS); environmental transformation

\section{Introducción}

Este artículo se deriva del proyecto de investigación URBI-SIG, vinculado al grupo de investigación Arquitectura, Medios de Expresión y Comunicación, de la Universidad Nacional de Colombia sede Manizales y del proyecto de investigación Indicadores de la calidad del espacio público efectivo, vinculado al grupo de investigación Gestión de la Infraestructura de Transporte y del Espacio Público. Adicionalmente, el punto de partida de la presente investigación se soportó en los resultados del trabajo con el semillero de investigación URBI-SIG.

Los estudios de investigación sobre la evolución morfológica de las ciudades colombianas se han centrado en ciudades con historias urbanas de la época colonial española, como el caso del análisis morfológico mediante superposición cartográfica de la ciudad de Ibagué, Tolima (Francel, 2017); el estudio de las formas de crecimiento urbano por periodos de estudio de Tunja, Boyacá (Hidalgo-Guerrero, 2008); la configuración de la estructura socioespacial de Ambalema, Tolima (Páez Trujillo, 2017); el caso de los cambios en la morfología urbana de Yolombó, Antioquia (Ochoa Villa, 2009), y el estudio de tramas y morfología urbanística en Cali, Valle del Cauca (Bonilla Sandoval, 1999).

En el presente artículo se explora una lectura de la ciudad de Manizales (Colombia), fundada por la migración y la colonización antioqueñas en la primera mitad del siglo XIX (1849), y la cual fue plaza fuerte y frontera en los conflictos 
económicos, culturales y religiosos entre los antiguos estados de Antioquia y Cauca (Pardo Rueda, 2004; Giraldo Mejía \& Mertins, 2000).

Manizales es la capital del departamento de Caldas y se localiza en el centro-occidente de Colombia, sobre la vertiente occidental de la Cordillera Central, a 2150 metros de altitud. Sus coordenadas geográficas son $5^{\circ} 04^{\prime} 15,3^{\prime \prime}$ latitud norte y $75^{\circ} 30^{\prime} 52,1^{\prime \prime}$ longitud oeste del meridiano de Greenwich (Ochoa Botero et al., 2013). La ciudad hace parte de un sistema urbano de carácter policéntrico conocido como Eje Cafetero colombiano (figura 1), integrado, además, por las ciudades de Pereira y Armenia, las cuales ejercen un dominio compartido en términos funcionales y económicos sobre centros urbanos circunvecinos de menor jerarquía (Gaviria Ríos, 2017).

El objetivo de este artículo es identificar y caracterizar las formas urbanas y la relación con los espacios públicos tomando en cuenta la topografía, la transformación ambiental y los procesos de gestión urbana vinculados a los desarrollos urbanísticos de los barrios y a las fases de crecimiento de la ciudad desde su fundación, en 1849, hasta la actualidad. Este propósito requirió el uso de un sistema de información geográfica (SIG), el cual facilitó la comprensión de la incidencia de las formas urbanas en la producción de espacios públicos y posibilitó la cuantificación y la caracterización de los espacios públicos según las áreas con tratamiento geotécnico (ATG).

Las formas urbanas han sido estudiadas desde diferentes enfoques y áreas del conocimiento. Alexander (2009 [1965]) planteó dos modelos de pensamiento: malla y árbol, para explicar los procesos de gestión urbana. Estos conceptos permitieron diferenciar entre ciudades naturales, que han sido desarrolladas de manera espontánea, y ciudades artificiales, concebidas desde la planificación urbana. El planteamiento de Alexander es explicado por Munizaga (1992), así: la malla es un sistema interdependiente, no jerárquico, con interconexión múltiple, y el árbol es el sistema opuesto, basado en una estructura jerárquica. Solá-Morales (1997) vinculó las formas de crecimiento urbano de los barrios, las calles, las manzanas y los edificios con los procesos de parcelación, urbanización y edificación, entendidos, en el caso colombiano, de acuerdo con la Ley 388 de 1997 (Congreso de Colombia), como actuaciones urbanísticas, o procesos de gestión necesarios para el desarrollo urbano.

Kropf (2017) determinó que las formas urbanas se estudian según cuatro enfoques: 1) de tipo morfológico, 2) de configuración, 3) histórico-geográfico y 4) de análisis espacial. Los dos primeros tienen su origen en los campos de la arquitectura y el urbanismo, mientras que los otros han surgido en el campo de la geografía. Las aproximaciones al tipo morfológico y al de

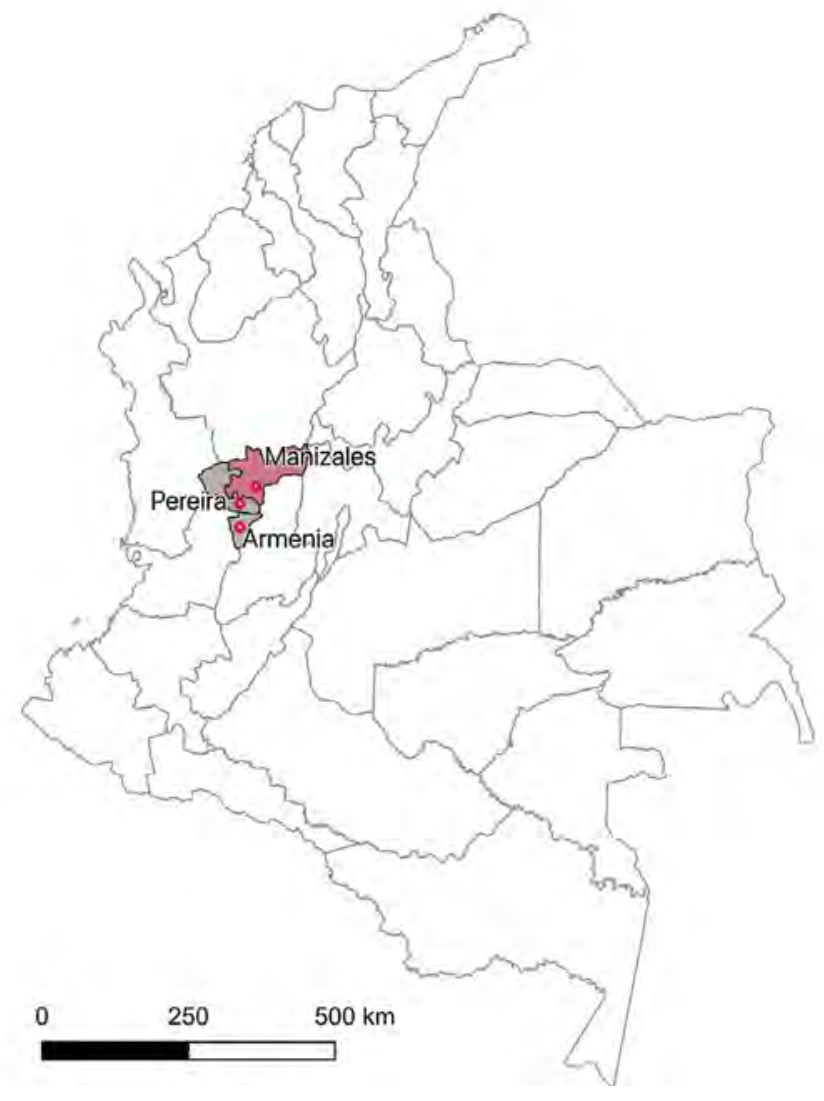

configuración buscan informar propósitos arquitectónicos y urbanos; principalmente, los relacionados con estructuras jerárquicas, procesos tipológicos y relación con el entorno.

En el enfoque morfológico, por su parte, se distinguen jerarquías compositivas, niveles de complejidad y formas según su posición dentro de la configuración urbana. Es posible identificar relaciones entre estos elementos, pues su capacidad de articularse y conectarse en diversas escalas define diferentes organizaciones (Alexander, 1980). Estos aspectos son expuestos por Munizaga (1992) en términos de jerarquías de organización: de control, de tecnología y de obsolescencia, las cuales se complementan con un sistema de interdependencia que permite integrar sistemas y subsistemas según el grado de complejidad de los núcleos urbanos.

En el enfoque de configuración, la forma urbana se estudia en términos de patrones geométricos, los cuales son el producto de un proceso que involucra la relación entre los habitantes y su entorno. En general, las ciudades están conformadas por los mismos elementos: calles, predios, manzanas y construcciones; sin embargo, la diversidad morfológica no se halla en los elementos, sino en la forma como se combinan generando diferentes tramas, algunas de las cuales son claramente identificables porque son tejidos urbanos singulares. Salazar Ferro (2017) considera que cuando las ciudades son organizadas con un patrón geométrico coherente de densidades, permiten orientar las decisiones de planeamiento, mientras que un carácter aleatorio confunde, no genera legibilidad y crea un caos en el patrón de uso del suelo.
(4) Figura 1. Localización de la ciudad de Manizales en el Eje Cafetero colombiano Fuente: Elaboración propia (2019) 


\begin{tabular}{|c|c|c|c|}
\hline Enfoque & Conceptos & Categorías & Variables \\
\hline \multirow{3}{*}{ Morfológico } & \multirow{3}{*}{$\begin{array}{l}\text { Estructuras } \\
\text { jerárquicas }\end{array}$} & Control & Tamaño de los elementos \\
\hline & & Jerarquías de tecnología & Escala funcional de un elemento \\
\hline & & Jerarquías de obsolescencia & Ciclos de uso y durabilidad de los elementos \\
\hline Configuración & $\begin{array}{l}\text { Atributos o patrones } \\
\text { geométricos }\end{array}$ & $\begin{array}{c}\text { Calles, predios, manzanas y } \\
\text { construcciones }\end{array}$ & $\begin{array}{l}\text { Configuraciones espaciales } \\
\text { Combinaciones de los elementos } \\
\text { Nivel de detalle }\end{array}$ \\
\hline \multirow{2}{*}{$\begin{array}{l}\text { Histórico- } \\
\text { geográfico }\end{array}$} & \multirow{2}{*}{$\begin{array}{l}\text { Estructura } \\
\text { geográfica }\end{array}$} & $\begin{array}{l}\text { Secuencias cronológicas de planos } \\
\text { de la ciudad }\end{array}$ & Tiempo \\
\hline & & $\begin{array}{c}\text { Carácter de los asentamientos } \\
\text { Cambios del proceso } \\
\text { desarrollo urbano }\end{array}$ & Tipos de asentamiento \\
\hline $\begin{array}{l}\text { Analítico } \\
\text { espacial }\end{array}$ & $\begin{array}{l}\text { Interacciones } \\
\text { espaciales }\end{array}$ & $\begin{array}{c}\text { Niveles de resolución o escala de } \\
\text { visualización }\end{array}$ & $\begin{array}{c}\text { Algoritmos digitales para el procesamiento de imágenes } \\
\text { Fractales } \\
\text { Redes }\end{array}$ \\
\hline
\end{tabular}

A Tabla 1. Síntesis de los enfoques morfológicos. Fuente: elaboración propia, con base en Alexander (1980), Munizaga (1992) y Kropf (2017).
Los estudios histórico-geográficos buscan explicar la estructura geográfica, las secuencias cronológicas de planos de la ciudad, los patrones y el carácter de los asentamientos humanos; es decir, en ellos se estudian los cambios del proceso de desarrollo urbano a través del tiempo. Cada uno de estos aspectos difiere por el factor tiempo, porque las ciudades son el resultado de un largo proceso donde se superponen capas. La noción de palimpsesto es a menudo utiliza$\mathrm{da}$, porque en la ciudad se reescribe sobre lo ya escrito (Oliveira, 2016).

El enfoque analítico espacial se centra, sobre todo, en un conjunto de interacciones espaciales utilizando métodos principalmente cuantitativos, como los fractales, el procesamiento de imágenes o los análisis de redes (Kropf, 2017). Cada ciudad posee características individuales y únicas, comúnmente denominadas tipos de estructura urbana determinados por factores físi$\cos$ y funcionales, lo que permite investigaciones ambientales y socioeconómicas asociadas (Voltersen, Berger, Hese \& Schmullius, 2014). Cuanto mayor sea el nivel de resolución, mayores serán el detalle de lo que se muestra y el nivel de especificidad de la descripción morfológica. En un nivel alto de resolución, el tejido puede incluir detalles como los materiales de construcción de un espacio público, y en un nivel bajo de resolución, por ejemplo, el tejido urbano solamente incluye las calles y las manzanas (Oliveira, 2016). La síntesis de estos enfoques y las variables propuestas se presentan en la tabla 1 .

El enfoque de análisis espacial se caracteriza por integrar otras disciplinas mediante el uso de SIG. Algunas investigaciones que abordaron este enfoque incluyeron la ecología urbana y utilizaron técnicas basadas en el análisis de conjuntos de atributos derivados de imágenes satelitales y fotografías aéreas, para clasificar tipos de estructuras urbanas según datos de teledetección y analizar los vínculos entre los asentamientos y los proble- mas ambientales en la ciudad de Berlín, Alemania (Voltersen, Berger, Hese \& Schmullius, 2014). Otras investigaciones incluyeron la medición de la forma urbana a escala de barrio de Dublín, Irlanda (Nedovic-Budic et al., 2016), la superposición cartográfica para la ciudad de Ibagué, Colombia (Francel, 2017) y la identificación y la clasificación de las formas urbanas de las ciudades capitales provinciales de Castilla-La Mancha, España (Prieto Medina et al., 2018).

La morfología de la ciudad es un tema de estudio complejo, porque incluye un vasto inventario de formas, que, a la vez, constituyen un todo y cambian según su aproximación desde los tejidos urbanos de una ciudad, pasando por los espacios públicos, los espacios de circulación y permanencia, hasta llegar a las manzanas, los bloques y los predios. Las formas urbanas son el resultado de políticas públicas, factores de crecimiento urbano y procesos de gestión, las cuales varían según los momentos históricos y las particularidades de cada ciudad.

En los desarrollos urbanísticos planificados, las formas pertenecientes a los procesos de parcelación y urbanización tienden a ser constantes en el tiempo; por ejemplo, el espacio público - exceptuando los casos de invasión del espacio público-, los equipamientos de transporte y las vías, los cuales forman parte de la totalidad de la ciudad, son suelos públicos, abarcan más área y requieren más tiempo para su desarrollo, mientras que las relacionadas con la edificación —es decir, los suelos privados- son más susceptibles al cambio de formas o de usos, porque dependen de las decisiones de sus habitantes, de proyectos de vida o de necesidades de inversión, como es el caso de las viviendas, y, generalmente, son unidades más pequeñas de carácter temporal.

La legibilidad urbana (Smith et al., 1999) permite comprender el lugar tanto en su forma física como en las actividades que se desarrollan en él. 
Oliveira (2016) plantea que en la actualidad se elogia la diversidad de formas urbanas; sin embargo, se alerta de una tendencia a la homogenización de los paisajes urbanos. Por ejemplo, el desarrollo de los suelos suburbanos se vuelve repetitivo por la falta de mezcla de usos del suelo: uso residencial de baja densidad, espacios para estacionamientos y hogares dependientes del vehículo (Bellet Sanfeliu, 2007). En cambio, la legibilidad es notoria en tramas reticulares, porque en ellas hay puntos de referencia y están pensadas para el peatón.

En el presente artículo se utilizaron los conceptos de estructuras jerárquicas y patrones geométricos de calles, predios, manzanas y construcciones. Las interacciones espaciales se realizaron mediante análisis de superposición de capas, mapa de pendientes y caracterización de las laderas.

\section{Lectura de Manizales a partir de sus formas urbanas}

La implantación de la ciudad de Manizales se caracteriza por estar en diferentes sectores de la montaña, como cimas, laderas intermedias, rellenos y vegas encañonadas, lo que ha generado un paisaje urbano con diversos patrones de ocupación y una restricción en la continuidad del tejido urbano (González-Plazas, 2009).

Los estudios en cuanto a las formas urbanas de Manizales han sido abordados desde diferentes escalas de aproximación y unidades de análisis, como los tipos de barrios representados en planos esquemáticos (Giraldo Mejía \& Mertins, 2000) y las formas urbanas que surgen del paisaje periurbano montañoso (González-Plazas, 2009). Otros enfoques incluyen el de la sostenibilidad — donde las estructuras construidas hacen parte de un sistema urbano integral- (Velásquez Barrero, 2010) y el de los periodos específicos, como la historia urbana durante el siglo XX (Satizábal Villegas, 2012) y factores de crecimiento urbano usando SIG (Cifuentes Ruiz \& Londoño Linares, 2010).

Se abarca la totalidad de los barrios de la ciudad según sus tramas urbanas y se definen criterios de selección para destacar algunos barrios que representan las tipologías identificadas, incluyendo los espacios públicos y las características de las laderas.

\section{Metodología}

El SIG utilizado fue el programa QGIS (Quantum GIS Development Team, 2017), para lo cual se utilizaron archivos en formato shape (.shp) de barrios, manzanas, espacios públicos, curvas de nivel y áreas de tratamiento geotécnico, obtenidos del SIG de la ciudad. Se vinculó una base de datos realizada por Márquez Duque (2010), con información de los barrios sobre su morfología urbana, su fecha de construcción y sus procesos de gestión urbana, con variables adicionales sobre espacios públicos y áreas de tratamiento geotécnico. Las características de estos elementos se combinaron mediante un análisis de superposición y se integraron a la base de datos.

A partir de las curvas de nivel, se realizó un modelo digital de elevación de terreno, y luego, un mapa de pendientes, para entender las formas urbanas según la topografía y la transformación ambiental sobre esta ocupación del territorio. La base de datos se actualizó, se depuró y se complementó con la información obtenida en el mapa de pendientes, lo que facilitó identificar patrones de ocupación del territorio, así como la clasificación y la caracterización de los barrios.

El inventario de espacios públicos se obtuvo del Acuerdo Municipal 958 de 2017 (Concejo de Manizales), y se consultó la cartografía oficial sobre espacios públicos (planos U-10 "Espacio Público" y U-11 "Sistema de Espacio Público"), la cual incluye las laderas ambientales urbanas. Se utilizó la base de datos relacional para describir, caracterizar y cuantificar los barrios y se intersectaron los espacios públicos con las áreas con tratamiento geotécnico (ATG).

Una vez organizada la información cartográfica, se seleccionaron las tramas que caracterizan la ciudad, las cuales se basaron en patrones según las formas urbanas, los tipos de manzanas, la distribución de sus predios y la estructura vial. También se consultó la cartografía oficial adoptada en el Acuerdo Municipal 663 de 2007 (Concejo Municipal de Manizales) sobre el suelo de protección urbana en los planos BU-63-1 "Laderas de protección", BU-62-1 "Áreas con tratamiento geotécnico", y AU-16-1 "Riesgo preliminar por deslizamiento urbano", y en el Acuerdo Municipal 958 de 2017 (Concejo Municipal de Manizales), los planos D-1 "Áreas de tratamiento geotécnico" y D-2B "Pendientes naturales del terreno urbanas".

La lectura urbana propuesta en este artículo aborda la identificación, la clasificación y la cuantificación de las tramas urbanas en la ciudad. Se identificaron tipologías de formas urbanas, como resultado de las adaptaciones topográficas, de las necesidades de sus habitantes, de las fases de crecimiento urbano $y$, en algunos casos, de las políticas de ordenamiento territorial, cuando fueron procesos planificados. Se agruparon los barrios según las tramas encontradas, con el fin de permitir un análisis detallado y comparativo del crecimiento urbano, la ocupación y la transformación ambiental del territorio.

En este artículo se presentan conceptos relacionados con la morfología urbana utilizada como herramienta para comprender y analizar las formas de crecimiento de Manizales según la transformación ambiental y su relación con los espacios públicos. 
Trama

Barrios

Cuadrícula

Centro, Los Agustinos, San Antonio

Retícula regular

Retícula irregular

Irregular

Orgánica

El Carmen, El Nevado, Pío XII

Radial

Sancancio, La Estrella, Aranjuez

Cul-de-sac y conjuntos cerrados

Cerros de la Alhambra, San Marcel, El Trébol

Lineal

Sacatín, Villapilar, Vivienda Popular

(A) Tabla 2. Barrios seleccionados por tramas.

Fuente: elaboración propia (2019).

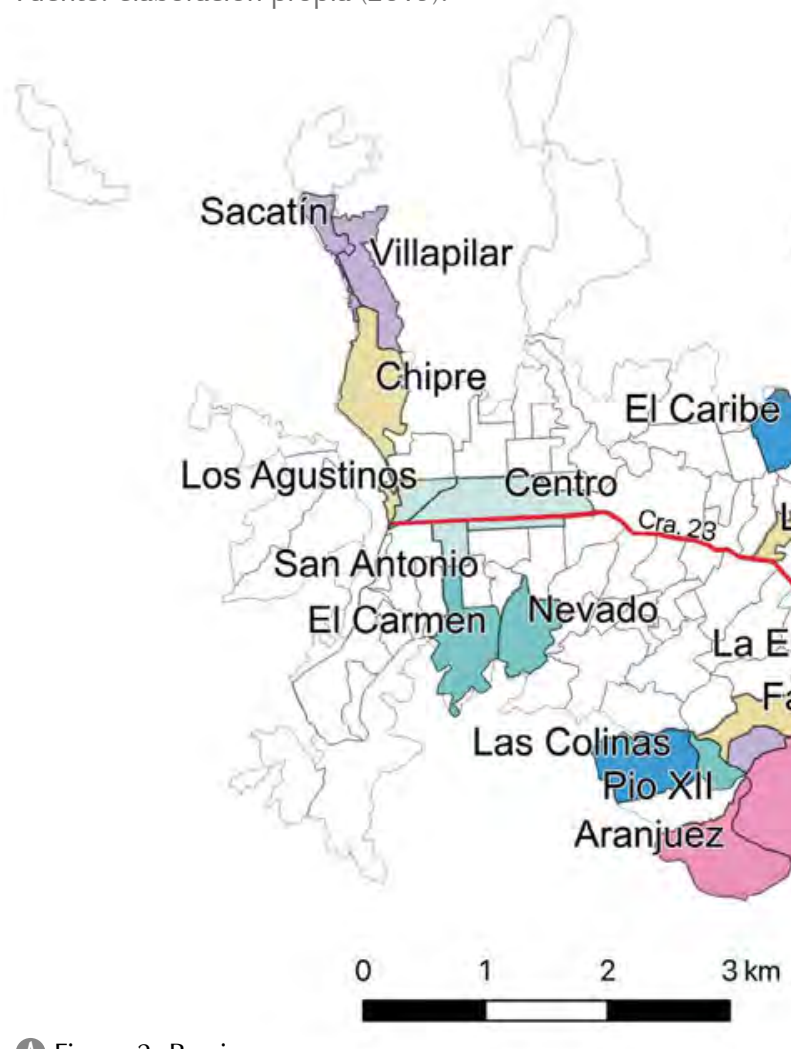

(A) Figura 2. Barrios

seleccionados por tramas.

Fuente: elaboración propia (2019).

$\rightarrow$ Figura 3. Trama de cuadrícula en los barrios Los Agustinos, Centro y San Antonio.

Fuente: elaboración propia (2019).

$\otimes$ Figura 4. Trama de retícula regular en el barrio La Enea. Fuente: elaboración propia (2019).

La Enea, La Sultana, Solferino

San Cayetano, El Caribe, Las Colinas

Fátima, La Argentina, Chipre

洒
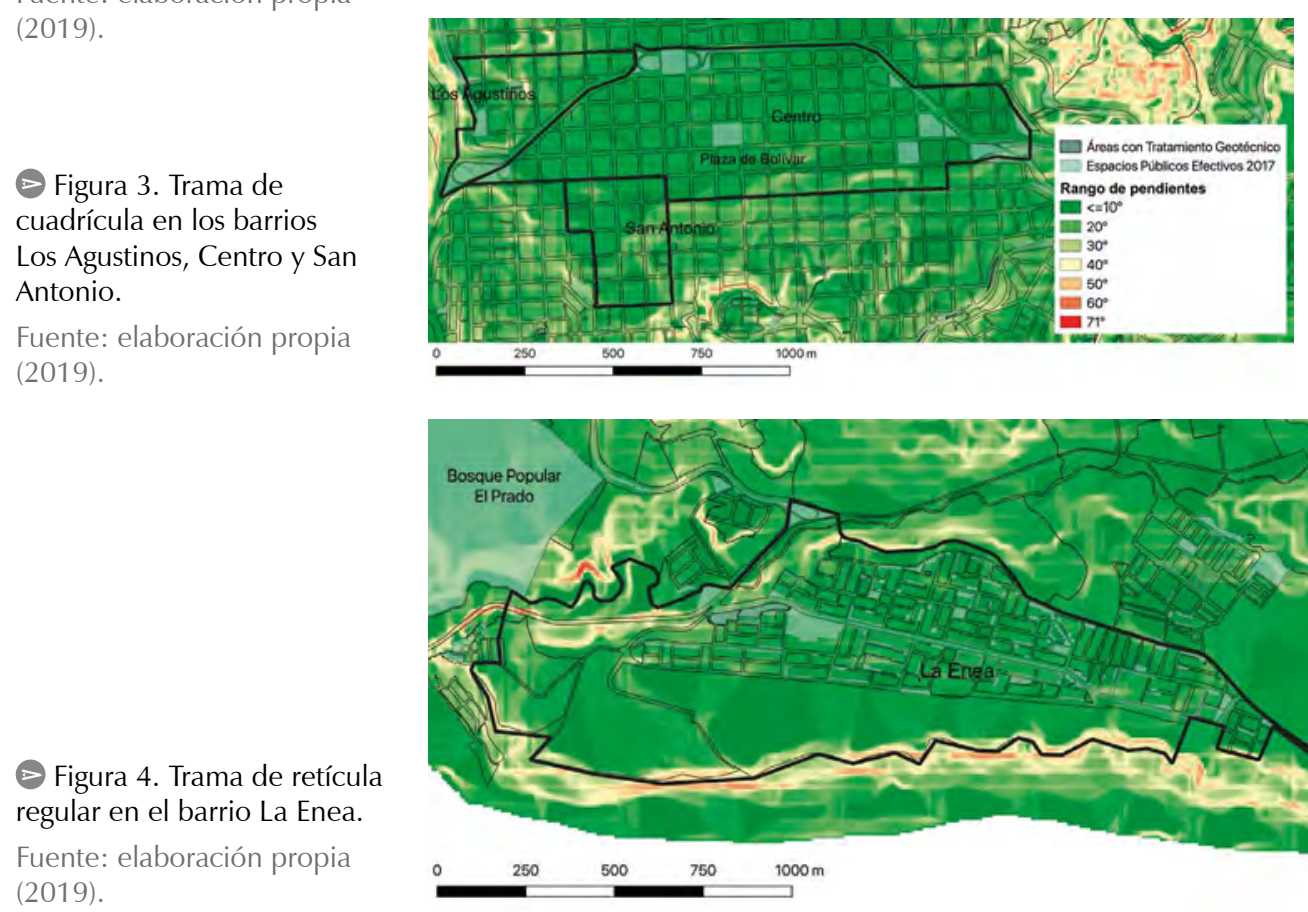

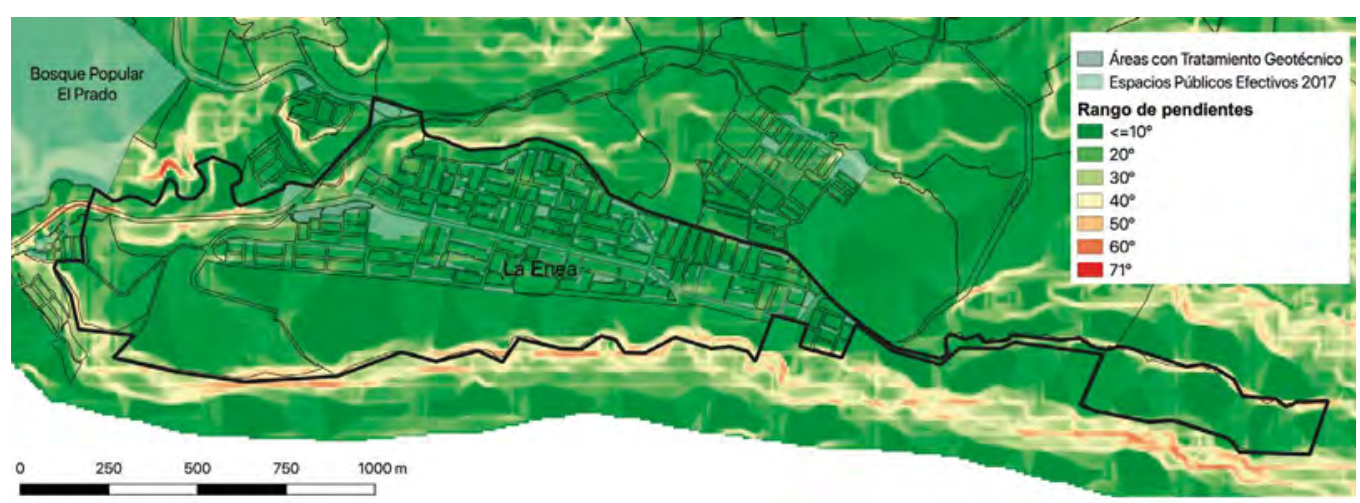

Tramas urbanas identificadas $\square$ Cul-de-sac y conjuntos cerrados $\square$ Irregular $\square$ Lineal Orgánica $\square$ Radial

$\square$ Retícula irregular $\square$ Retícula regular $\square$ Cuadrícula

\section{Resultados}

Se identificaron ocho tramas urbanas y se seleccionaron tres barrios según el tipo de trama, la relación con sus espacios públicos y la disposición de sus vías (tabla 2; figura 2). Las tramas se agruvial de interconexión múltiple sin una estructura orgánica, lineal y radial, y 3) las que no configuran zistema vial jerármejor las tipologías encontradas.

as tramas identificadas (figura 2) representan formas urbanas para su entendimiento y su trans-

Cul-de-sac es una expresión de origen francés que traduce calle sin salida. Se asocia a un patrón dendrítico, caracterizado por tener un tronco que se subdivide en pequeñas ramas (Thadani, 2010)

Cerros de la Alhambra 


\section{Tramas que configuran retículas}

\section{Cuadrícula}

Es una retícula también conocida como trama de damero, y la cual usa cuadrados que varian entre 60 y $65 \mathrm{~m}$ en la configuración de manzanas. La primera cuadrícula corresponde al inicio de la ciudad, y es reconocida como el Centro. Se la localizó en el lugar menos pendiente de la cima de la montaña, mediante el corte y el relleno de la parte alta de los drenajes naturales, y en ella se reservó suelo para algunos de sus espacios públicos principales en cuadrantes completos, que en la actualidad representan los espacios públicos de carácter cívico de la urbe. La mayoría de estas manzanas cuadradas se construyeron en pendientes inferiores a $30^{\circ}$. Con este mismo patrón geométrico, se construyeron los barrios San Antonio y Los Agustinos, a mediados del siglo XIX, sobre una topografía moderada, lo cual obligó a la construcción de viviendas adaptadas a la ladera. Como se observa en la figura 3, el barrio San Antonio no posee ningún espacio público. En la ciudad solo se encuentra dicha trama en el centro fundacional.

\section{Retícula regular}

Es una trama que usa formas regulares en la configuración de sus manzanas. Incluye formas ortogonales, triangulares y trapezoidales. Algunos de sus desarrollos urbanísticos están ligados a políticas de desarrollo urbano del Gobierno nacional para la construcción de vivienda de interés social. Los barrios seleccionados para explicar esta tipología son La Enea, La Sultana y Solferino, construidos durante la década de 1970.

Esta tipología es más flexible para implantarse en pendientes inferiores a $40^{\circ}$. La Enea (figura 4) y La Sultana (figura 5) se desarrollaron con procesos de urbanización donde se evidencia una uniformidad morfológica, mientras que en Solferino fue un proceso de agregación de viviendas diversas (figura 6). Los tres barrios configuran secciones del perímetro urbano de la ciudad. En La Enea se observa el control topográfico de la ladera norte de la quebrada Manizales.

Los barrios La Enea y La Sultana fueron concebidos como procesos expansivos de vivienda de interés social y primeras áreas de expansión urbana alejadas del centro fundacional por fuera de la estructura urbana principal (Satizábal Villegas, 2012), y aún corresponden a la periferia de la ciudad. Se destaca La Enea por la cantidad de zonas verdes, que constituyen también espacios públicos.

\section{Retícula irregular}

Esta tipología de trama crea continuidad en sus calles a pesar de la irregularidad en la forma de sus manzanas. Ha sido utilizada en pendientes inferiores a $50^{\circ}$; por lo tanto, sus formas urbanas varían de orientación según como se adecuan a las condiciones topográficas. Los barrios seleccionados para ejemplificar esta tipología son El Caribe, San Cayetano y Las Colinas, los cuales se caracterizan por estar delimitados por áreas de terreno con pendientes fuertes.

Los nuevos suelos destinados al uso residencial construidos en la década de 1990, como el barrio El Caribe (figura 7), cuentan con zonas verdes residuales sin diseño, en contraste con los espacios públicos concebidos para el desarrollo urbanístico de La Enea (figura 4). San Cayetano (figura 7) se caracteriza por tener un crecimiento

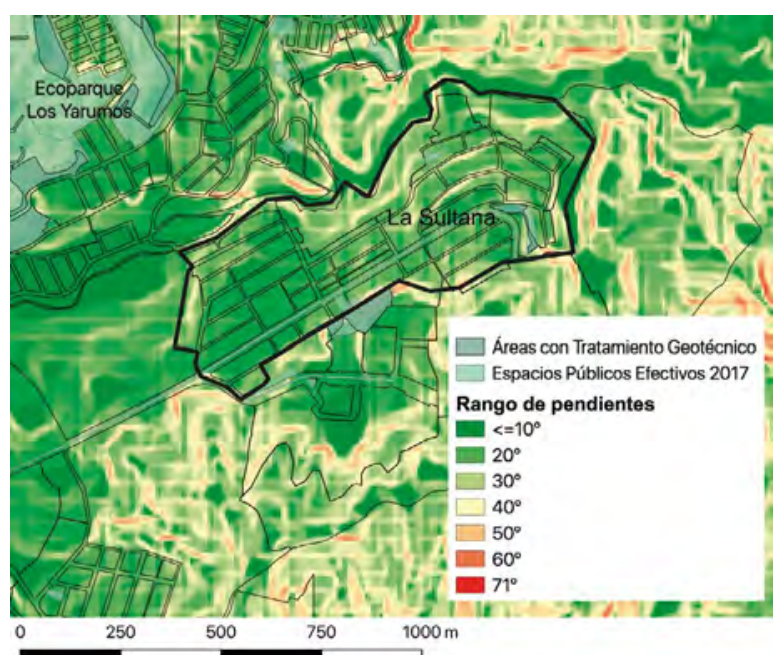

Figura 5. Trama de retícula regular en el barrio La Sultana. Fuente: elaboración propia (2019).

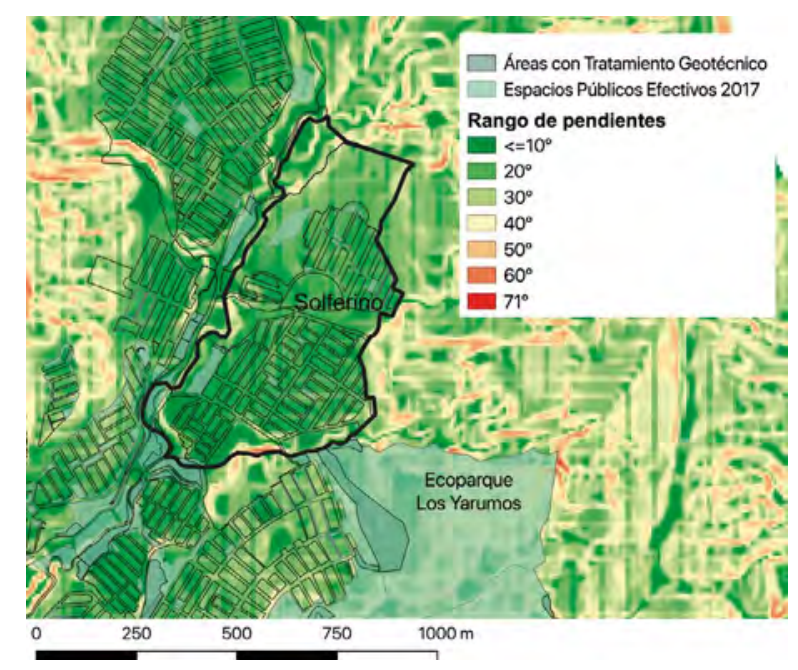

(4) Figura 6. Trama reticular en el barrio Solferino.

Fuente: elaboración propia (2019).

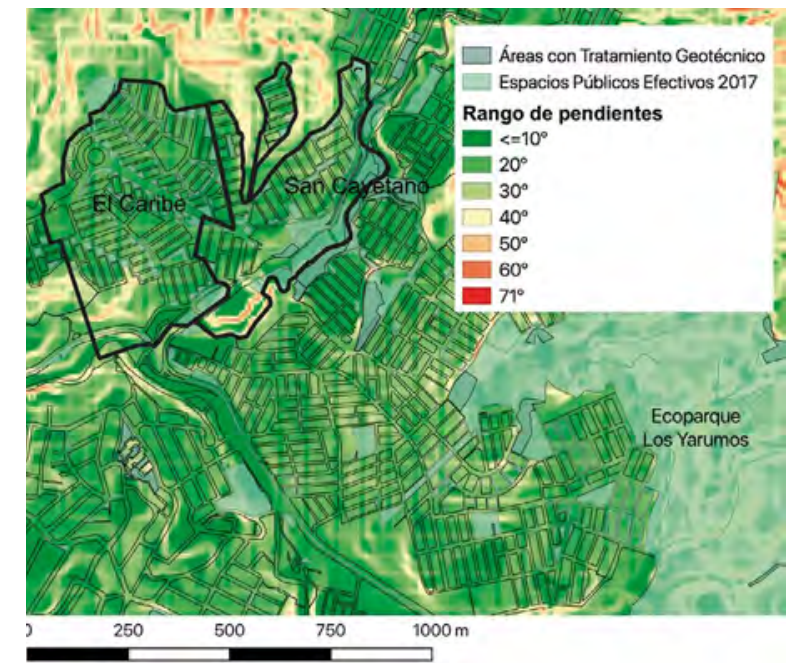

\& Figura 7. Trama de retícula irregular en los barrios El Caribe y San Cayetano. Fuente: elaboración propia (2019). 
๑ Figura 8. Trama de retícula irregular en el barrio Las Colinas.

Fuente: elaboración propia (2019).

จ Figura 9. Trama irregular en el barrio Chipre.

Fuente: elaboración propia (2019).

๑ Figura 10. Trama irregular en el barrio La Argentina.

Fuente: elaboración propia (2019).

๑ Figura 11. Trama irregular en el barrio Fátima.

Fuente: elaboración propia (2019).

$\ominus \ominus$ Figura 12. Trama orgánica en los barrios El Carmen y El Nevado.

Fuente: elaboración propia (2019).

$\ominus \ominus$ Figura 13. Trama orgánica en el barrio Pío XII. Fuente: elaboración propia (2019).

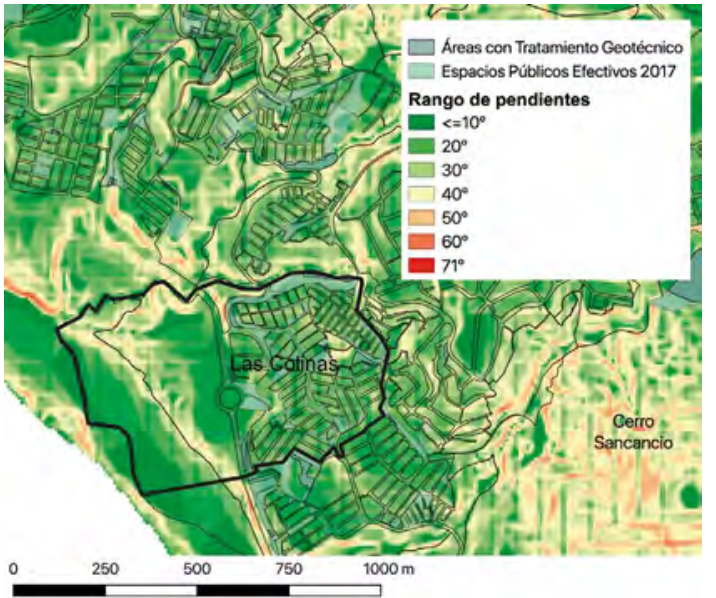

ramificado, como un sistema dactilar, debido a las diferencias topográficas entre cada polígono urbanizado, que no permiten la integración del desarrollo urbanístico. Las Colinas (figura 8) se caracteriza por una diversidad de formas y disposición de sus manzanas con la intención de adaptarse a la ladera, con el riesgo de construir infraestructura superficialmente cimentada sobre un terreno sin preparación para recibir las nuevas cargas estructurales.

\section{Tramas que no configuran retículas}

\section{Irregular}

Es una trama caracterizada por una mezcla de formas y tamaños con manzanas heterogéneas. Esta trama no configura una retícula, porque sus calles son discontinuas, con diversas conexiones viales y múltiples orientaciones, las cuales generan sinuosidad en el recorrido y dificultad en la búsqueda de un lugar. Los barrios seleccionados para explicar esta tipología son Fátima, La Argentina y Chipre.

Estos barrios se caracterizan por tener visuales sobre el paisaje, debido a su implantación en la montaña o en el borde de una ladera, como es el caso de Chipre, donde se observa el cambio de pendientes en el costado oriental junto a la ladera perimetral al casco urbano (figura 9). El origen del barrio coincide con el agotamiento de suelos urbanizables con pendientes inferiores a $20^{\circ}$ a lo largo de la década de 1950.

La Argentina es un barrio conformado por diez manzanas (figura 10). Aunque no posee espacios públicos, está localizado junto a dos parques deportivos: La Asunción y La Leonora.

Fátima se localiza junto al cerro Sancancio, el cual es un referente del paisaje de Manizales. Su irregularidad morfológica se debe a la adaptación al terreno. Sus manzanas se encuentran a diferentes alturas y sus calles tienen pendientes de hasta $40^{\circ}$ (figura 11 ).

\section{Orgánica}

Esta trama se caracteriza por tener un desarrollo urbano aleatorio, carente de simetría y sin un orden aparente, propio de las formas de crecimiento urbano espontáneo. Prevalecen las

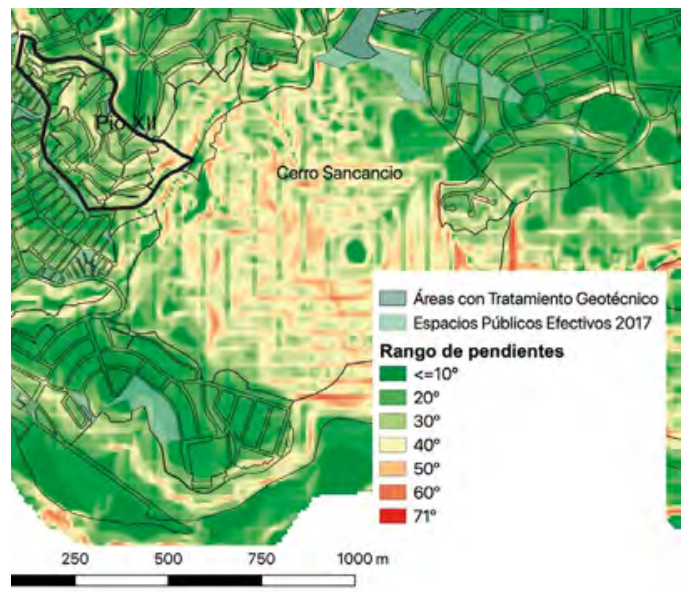


formas cóncavas y convexas adaptadas a las condiciones de la topografía. Los barrios El Nevado, El Carmen y Pío XII se configuraron a través de agregación de manzanas y viviendas con un proceso de autogestión.

El Nevado y El Carmen (figura 12) revelan diferentes etapas de desarrollo urbanístico, con formas de crecimiento regulares ortogonales e irregulares y tamaños variables de viviendas. Su proximidad al centro de la ciudad evidencia algunas manzanas cuadradas y rectangulares, producto de la intervención municipal.

El barrio Pío XII se destaca por la heterogeneidad de sus formas urbanas; posee escaleras urbanas para superar la fuerte pendiente y calles estrechas, con dificultades para la movilidad vehicular. Las condiciones escenográficas del paisaje son aprovechadas para la distribución de viviendas escalonadas y desaprovechadas para la configuración de espacio público. Lo poco que hay son espacios residuales sin ningún atractivo visual, a pesar de su proximidad al cerro Sancancio, como se observa en la figura 13. La configuración de sus calles permite identificar una trama en forma de espina de pescado, adaptada a la ladera, que les genera organicidad a sus manzanas, entendida como una diversidad morfológica con formas sinuosas.

\section{Radial}

Es una trama radiocéntrica conformada por un amplio círculo con vías radiales que emanan desde el centro, facilitan la circulación y generan

(1) Figura 14. Trama radial en el barrio La Estrella. Fuente: elaboración propia (2019).
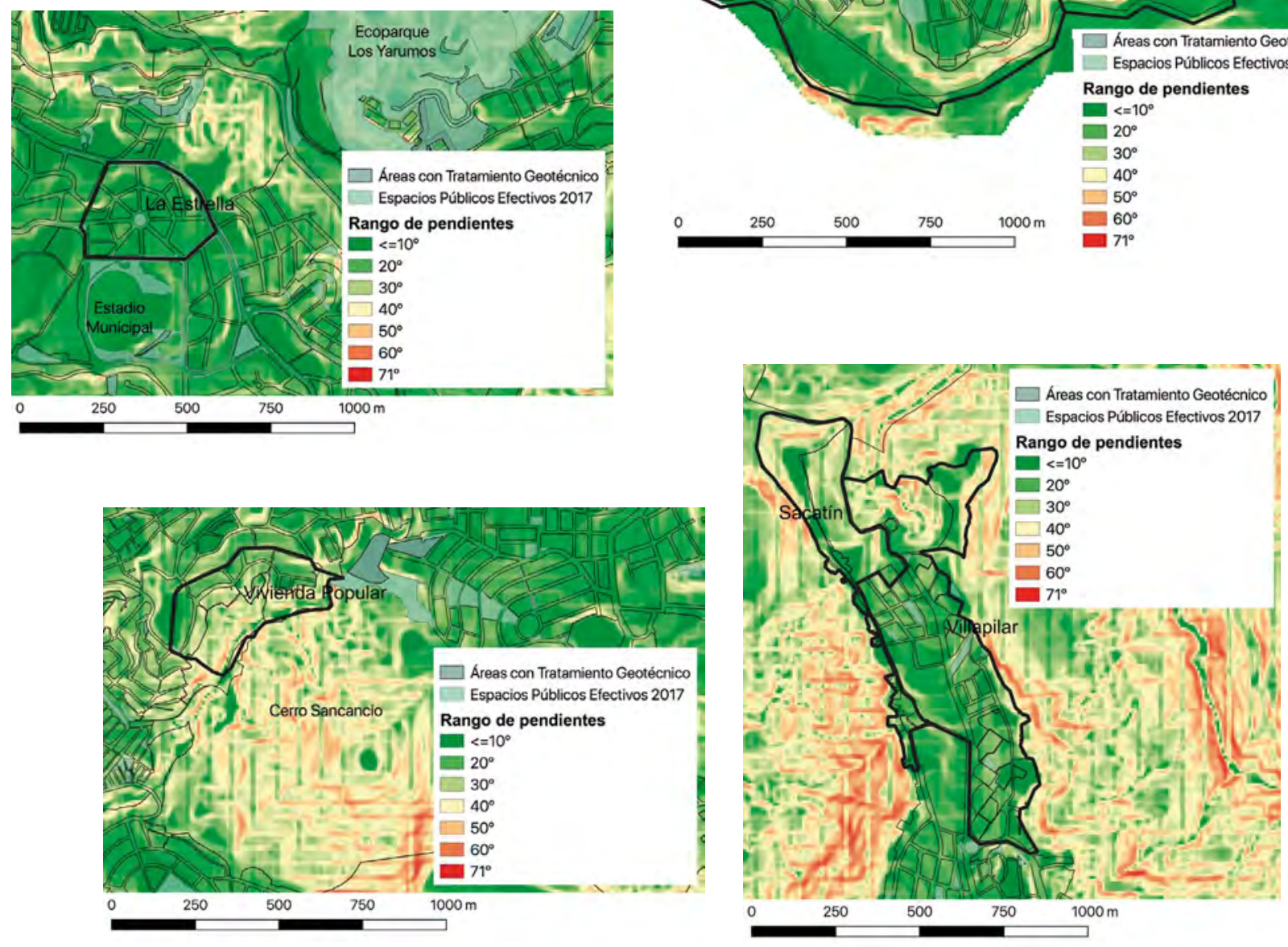

8 Figura 16. Trama lineal en el barrio Vivienda Popular. Fuente: elaboración propia (2019).

(4) Figura 17. Trama lineal en los barrios Sacatín y Vivienda Popular. Fuente: elaboración propia (2019). 
circular ni una calle alrededor (figura 15), pero se cuenta con el parque deportivo, atractivo para toda la ciudad en cuanto a la organización de torneos de fútbol.

\section{Lineal}

Esta trama está configurada a lo largo de los costados de una vía principal, donde se diferencian un origen y un destino, y no configura un centro. Se presenta en la cima de la continuidad del área que ocupa el Centro y se encuentra ligada a un desarrollo urbanístico a lo largo del camino. Por lo general, es el resultado de las condiciones topográficas que limitan su crecimiento; se encuentra en forma de espina de pescado, con ramificaciones o como un enrejado. Los barrios seleccionados para explicar esta tipología fueron Vivienda Popular, Sacatín y Villapilar, los cuales se desarrollaron en áreas distantes del centro de la ciudad y de la carrera 23. El barrio Vivienda Popular (figura 16) se caracteriza por tener manzanas en distintas pendientes. La configuración de las manzanas no tuvo en cuenta el valor paisajístico que representa el cerro Sancancio; dicho valor solo puede ser disfrutado desde los patios de las viviendas localizadas de espalda al cerro.

(1) Figura 18. Trama cul-de-sac y conjuntos cerrados en los barrios El Trébol y San Marcel. Nota: se presentan los predios, en ausencia de manzanas definidas en esta trama. Fuente: elaboración propia (2019).
Aunque el primer proceso de expansión urbana de Manizales, en 1944, inició de forma lineal en la cima de la actual carrera 23, también conocida como Avenida Santander, sobre esta vía no se construyeron barrios de trama lineal. De forma semejante, en la continuidad de la cima de la

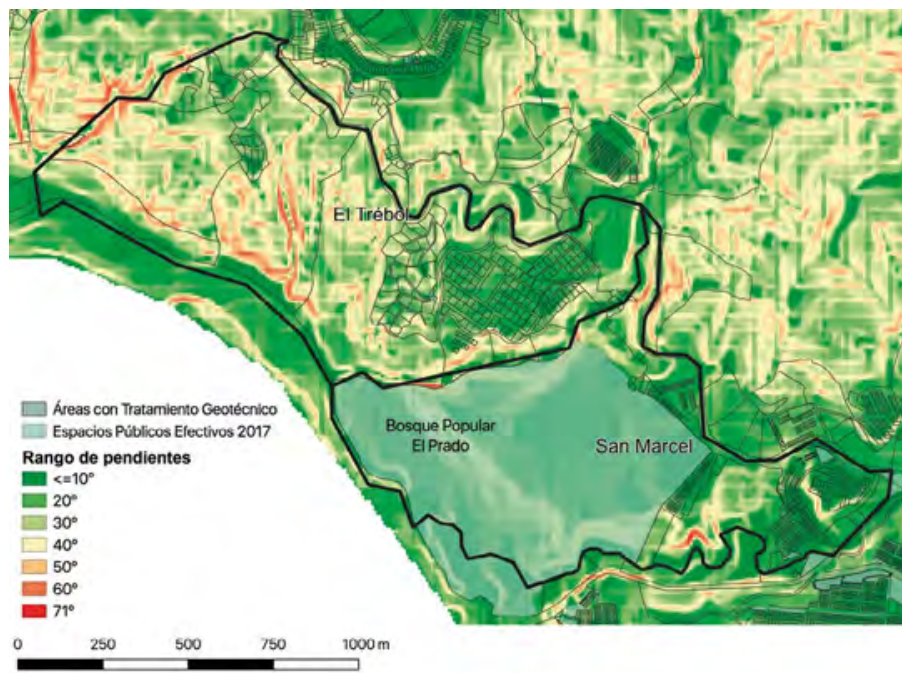

$\rightarrow$ Figura 19. Trama cul-desac y conjuntos cerrados en el barrio Cerros de La Alhambra. Nota: se presentan los predios, en ausencia de manzanas definidas en esta trama.

Fuente: elaboración propia (2019). ladera perimetral de Chipre se construyeron los barrios Sacatín y Villapilar (figura 17).

Tramas que no configuran manzanas

\section{Cul-de-sac y conjuntos cerrados}

Esta trama es común en asentamientos periurbanos y suburbanos, y se asocia a dendritas o ramas de un árbol que conforman una estructura jerárquica, con calles no interconectadas. En el tejido urbano se genera discontinuidad y fraccionamientos en el territorio, porque se configuran como enclaves urbanos. El acceso a estos se ramifica en el interior en vías menores o en culde-sac (calles sin salida), que conforman polígonos amorfos, y no manzanas. La configuración de los barrios Cerros de La Alhambra, San Marcel y El Trébol corresponde a urbanizaciones con conjuntos cerrados destinados a viviendas de alto valor comercial.

Este tipo de trama no ofrece espacios públicos. Los lugares de encuentro están en el interior de los conjuntos cerrados y son de uso exclusivo para sus habitantes. Se desarrollan bolsas de terreno insulares que agrupan conjuntos cerrados para viviendas, y algunos, sin considerar el acceso peatonal. "Su enclavamiento físico refuerza el aislamiento y separación con el entorno, generando un territorio socialmente fragmentado" (Capron \& Esquivel Hernandez, 2016, p. 147).

Los barrios El Trébol y San Marcel (figura 18) están localizados junto al Parque Bicentenario, también conocido como el Bosque Popular, que es un gran espacio público construido en la segunda mitad del siglo XX, a partir de la transformación de un club campestre privado, y antecede a la construcción de estos barrios. La disposición de los predios en el barrio Cerros de La Alhambra, (figura 19) obedece al diseño de la vía sinuosa que se desarrolla a lo largo de la pendiente. Las viviendas de este barrio se localizan en distintos rangos de pendientes que oscilan entre $10^{\circ}$ y $30^{\circ}$.

\section{Tramas según fases de crecimiento urbano}

Los factores que influyeron en la conformación de las diferentes tramas y su producción de espacio público varían según la topografía, la implantación urbana y el tipo de ciudad propuesta, acorde con los momentos históricos de la ciudad. Se pueden definir cinco fases de crecimiento, según Rivera Pabón (2013), para la ciudad de Manizales, por analogía con las ciudades vecinas de Pereira y Armenia, con las cuales conforma un sistema que surgió del proceso de colonización agraria, relacionado con la caficultura, de la zona central andina de Colombia durante el siglo XIX:

- Colonización agraria e instauración del modelo de desarrollo cafetero (1849-1930): durante este periodo se promueve el poblado urbano producto de la colonización agraria, y, a su vez, la implementación del modelo de desarrollo agroexportador cafetero. 


\begin{tabular}{|c|c|c|c|c|c|c|c|c|c|c|}
\hline $\begin{array}{c}\text { Fases de } \\
\text { crecimiento }\end{array}$ & Cuadrícula & $\begin{array}{l}\text { Retícula } \\
\text { regular }\end{array}$ & $\begin{array}{l}\text { Retícula } \\
\text { irregular }\end{array}$ & Irregular & Orgánica & Radial & $\begin{array}{l}\text { Cul-de-sac } \\
\text { y conjuntos } \\
\text { cerrados }\end{array}$ & Lineal & Subtotal & $\%$ \\
\hline \multirow{2}{*}{ Anteriores a 1930} & 5 & 0 & 0 & 0 & 0 & 0 & 0 & 0 & 5 & \multirow{2}{*}{$4 \%$} \\
\hline & $100 \%$ & $0 \%$ & $0 \%$ & $0 \%$ & $0 \%$ & $0 \%$ & $0 \%$ & $0 \%$ & $100 \%$ & \\
\hline \multirow{2}{*}{ 1930-1950 } & 3 & 1 & 3 & 1 & 2 & 0 & 0 & 2 & 12 & \multirow{2}{*}{$11 \%$} \\
\hline & $25 \%$ & $8 \%$ & $25 \%$ & $8 \%$ & $17 \%$ & $0 \%$ & $0 \%$ & $17 \%$ & $100 \%$ & \\
\hline \multirow{2}{*}{ 1951-1970 } & 0 & 4 & 8 & 7 & 8 & 1 & 0 & 3 & 31 & \multirow{2}{*}{$27 \%$} \\
\hline & $0 \%$ & $13 \%$ & $26 \%$ & $23 \%$ & $26 \%$ & $3 \%$ & $0 \%$ & $10 \%$ & $100 \%$ & \\
\hline \multirow{2}{*}{ 1971-1993 } & 0 & 9 & 14 & 9 & 0 & 1 & 0 & 1 & 34 & \multirow{2}{*}{$30 \%$} \\
\hline & $0 \%$ & $26 \%$ & $41 \%$ & $26 \%$ & $0 \%$ & $3 \%$ & $0 \%$ & $3 \%$ & $100 \%$ & \\
\hline \multirow{2}{*}{ 1994-2018 } & 0 & 9 & 7 & 8 & 0 & 1 & 4 & 3 & 32 & \multirow{2}{*}{$28 \%$} \\
\hline & $0 \%$ & $28 \%$ & $22 \%$ & $24 \%$ & $0 \%$ & $3 \%$ & $13 \%$ & $9 \%$ & $98 \%$ & \\
\hline \multirow{2}{*}{ Total } & 8 & 23 & 32 & 25 & 10 & 3 & 4 & 9 & 114 & \multirow{2}{*}{$100 \%$} \\
\hline & $7 \%$ & $20 \%$ & $28 \%$ & $22 \%$ & $9 \%$ & $3 \%$ & $4 \%$ & $8 \%$ & $100 \%$ & \\
\hline
\end{tabular}

(1) Tabla 3. Número de barrios por tramas y fases de crecimiento. Fuente: elaboración propia (2019), con base en información obtenida de Márquez Duque (2010).

\begin{tabular}{|c|c|c|c|c|c|c|c|c|}
\hline $\begin{array}{c}\text { Fases de } \\
\text { crecimiento }\end{array}$ & Cuadrícula & $\begin{array}{l}\text { Retícula } \\
\text { regular }\end{array}$ & $\begin{array}{l}\text { Retícula } \\
\text { irregular }\end{array}$ & Irregular & Orgánica & Radial & $\begin{array}{c}\text { Cul-de-sac y } \\
\text { conjuntos cerrados }\end{array}$ & Lineal \\
\hline Anteriores a 1930 & $\begin{array}{c}\text { Centro } \\
\text { Los Agustinos }\end{array}$ & & & & & & & \\
\hline 1930-1950 & San Antonio & & Las Colinas & & El Carmen & & & Sacatín \\
\hline $1951-1970$ & & & & $\begin{array}{l}\text { Chipre } \\
\text { Fátima }\end{array}$ & $\begin{array}{l}\text { El Nevado } \\
\text { Pío XII }\end{array}$ & La Estrella & & $\begin{array}{l}\text { Vivienda } \\
\text { Popular }\end{array}$ \\
\hline 1971-1993 & & $\begin{array}{c}\text { La Enea } \\
\text { La Sultana } \\
\text { Solferino }\end{array}$ & San Cayetano & La Argentina & & Aranjuez & & Villapilar \\
\hline 1994-2018 & & & El Caribe & & & Sancancio & $\begin{array}{c}\text { Cerros de la Alhambra } \\
\text { El Trébol } \\
\text { San Marcel }\end{array}$ & \\
\hline
\end{tabular}

- Modernización local (1930-1950): consolidación del sector agrario e incursión de emprendimientos industriales. Se inicia un proceso de diferenciación socioespacial: por un lado, un crecimiento espontáneo con tramas orgánicas, y, por otro, "el desarrollo de un sector de élite, que presenta innovaciones en su división parcelaria, morfología urbana y diseño arquitectónico" (Rivera Pabón, 2013, p. 255).

- Periodo de La Violencia y migración campo-ciudad (1950-1970): el crecimiento urbano de esta época estuvo acompañado de un aumento poblacional de origen campesino, lo que incrementó la diferenciación socioespacial.

- Bonanza cafetera y desarrollismo (19701990): el crecimiento de la ciudad está acompañado de "altos niveles de productividad del sector agroindustrial cafetero" (Rivera Pabón, 2013, p. 300). También hubo atracción de nuevos pobladores y desarrollos urbanos en la periferia de la ciudad.

- Apertura económica (1990-2018): el crecimiento urbano de esta época se caracteriza por un proceso de desconcentración y relocalización suburbana de usos residenciales, industriales y equipamientos colectivos, lo que generó un carácter disperso de funciones urbanas. También se incrementa el desarrollo de conjuntos residenciales cerrados y de centros comerciales.

Los 114 barrios de la ciudad se caracterizaron según las 5 fases de crecimiento y las 8 tramas urbanas identificadas (tabla 2). La sumatoria de las tramas en cada periodo corresponde a la forma de presentación de resultados propuesta por Bonilla Sandoval (1999) para el estudio de la morfología de la ciudad de Cali (Colombia).

A partir de 1950, el proceso de ocupación del suelo se intensificó, el área urbanizada aumentó y surgieron las formas espontáneas correspondientes a tramas orgánicas. El crecimiento urbano a partir de la fase de apertura económica, en 1990, produjo un aumento del $28 \%$ del total de barrios, 4 de los cuales pertenecen a urbanizaciones cerradas localizadas en la periferia.

En la segunda mitad del siglo XX no se volvieron a utilizar las manzanas de forma cuadrada propias de la cuadrícula, tal como se evidencia
(A) Tabla 4. Barrios seleccionados en el estudio, organizados por fase de crecimiento y por tipo de trama.

Fuente: elaboración propia (2019). 
(7) Figura 20. Número de Áreas de Tratamiento Geotécnico (ATG) o espacios públicos por trama para 2017.

Fuente: elaboración propia, con base en la información obtenida de los archivos shapes (.shp) de áreas con tratamiento geotécnico y espacio público a 2017 de la Alcaldía Municipal de Manizales. en las fases de crecimiento (tabla 3). Debido a la total ocupación de los suelos menos pendientes del territorio, la expansión urbana posterior se realizó en diferentes sectores de la montaña, como lo establece González-Plazas (2009). A partir de 1970 no se volvió a utilizar la trama orgánica; el aumento poblacional de origen campesino sucedió entre 1950 y 1970, correspondiente ello con el periodo de La Violencia y de la migración campo-ciudad (Rivera Pabón, 2013), donde se establecieron los nuevos habitantes de origen campesino, quienes definieron espacialmente las áreas que luego configuraron barrios como El Carmen, El Nevado y Pío XII. Los 24 barrios seleccionados se organizaron según las fases de crecimiento y las tramas identificadas, lo que permite observar la aparición de los barrios a lo largo de la historia urbana de la ciudad (tabla 4).

\section{Ocupación y transformación ambiental del territorio}

El mayor número de espacios públicos y de áreas con tratamiento geotécnico de la ciudad se concentra en los barrios con tramas irregular, de retícula regular y de retícula irregular, los cuales suman el $70 \%$ de los 114 barrios de Manizales (figura 20).

Se resalta cómo la trama que tiene menos áreas con tratamiento geotécnico es la cuadrícula, pero debe tenerse en cuenta que los tratamientos geotécnicos reportados en la documentación oficial corresponden a obras de estabilidad de laderas, mientras que el área fundacional de la ciudad se hizo mediante el lleno y la intercep- ción de drenajes naturales. El estado de dichos rellenos al cabo de las décadas amerita una valoración tanto o más rigurosa que la de las laderas en la cuales se enfoca la gestión del riesgo de la ciudad.

Muchas de las zonas verdes de la ciudad son laderas, incluyen arborización en franjas de amoblamiento, islas de vegetación y taludes con y sin tratamientos geotécnicos y separadores viales. Además, son espacios residuales, no cuentan con diseño de espacio público y no permiten el uso recreativo por sus pendientes; al contrario de ciudades localizadas en topografías planas, donde se favorece el uso recreativo y no hay tratamientos geotécnicos.

Según el Acuerdo Municipal 958 de 2017 (Concejo de Manizales), las laderas urbanas cumplen funciones de conectividad y paisajísticas, incluyen relictos boscosos y pendientes superiores a $\operatorname{los} 40^{\circ}$, que permiten moderar movimientos en masa, inundación o avenidas correccionales. En 2017, algunas laderas urbanas ya incluían áreas con tratamiento geotécnico para la estabilización de taludes y otras correspondían a espacios públicos. Además, en el mencionado acuerdo se propuso aumentar el espacio público recuperando laderas urbanas mediante obras de bioingeniería y reforestación, las cuales se clasifican actualmente como suelo de protección y prestan servicios ambientales colectivos, y pasarían a ser elementos constitutivos naturales del espacio público. Si bien las zonas verdes y las laderas urbanas recuperadas contribuyen a aumentar el espacio público, no permiten el uso recreativo ni la permanencia en el lugar por su pendiente.

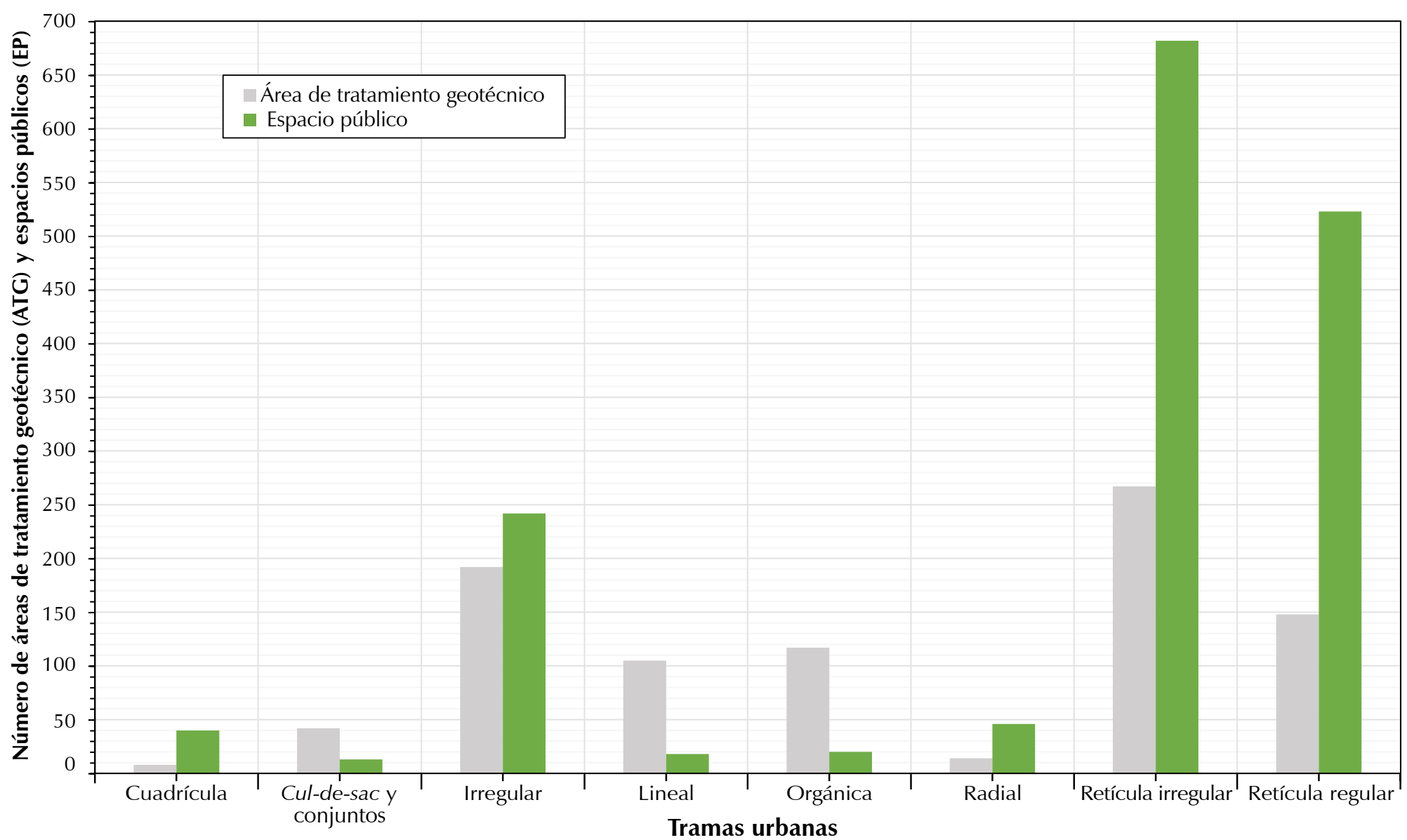




\begin{tabular}{ccc} 
Laderas urbanizadas & $\begin{array}{c}\text { Laderas perimetrales al casco urbano } \\
\text { (áreas de interés ambiental) }\end{array}$ & Laderas de protección ambiental \\
$\begin{array}{c}\text { Centro, La Estrella, } \\
\text { San Antonio }\end{array}$ & Chipre, Los Agustinos, Sacatín, Sancancio & $\begin{array}{c}\text { Cerros de la Alhambra, Aranjuez, El Caribe, El Trébol, Fátima, La Argentina, } \\
\text { La Enea, La Sultana, Las Colinas, El Nevado, Pío XII, Vivienda Popular, San } \\
\text { Cayetano, San Marcel, Solferino }\end{array}$ \\
\hline
\end{tabular}

Por lo general, en las condiciones predominantes del terreno en la ciudad de Manizales las áreas de tratamiento geotécnico corresponden a elementos para la estabilización de taludes y laderas, tales como sistemas de drenaje superficial y subterráneo, elementos de ingeniería tradicional como muros de contención, anclajes y pantallas, y elementos de bioingeniería como cercos vivos, trinchos y otras medidas de recuperación de la cobertura vegetal. En consecuencia, las áreas de tratamiento geotécnico tienen muy poca flexibilidad para adaptarse a otros usos tanto por su morfología, incompatible con los requerimientos de los usuarios en términos de accesibilidad y confort, como por el riesgo implícito, que ha sido mitigado, pero no eliminado, con la construcción de las obras.

En algunos casos, las áreas con tratamiento geotécnico aportan al beneficio general de todos los habitantes de la ciudad, como es contribuir a la estabilización de una vía, mientras que otras solo benefician a los habitantes de un sector específico. El riesgo geotécnico afecta por igual a los desarrollos de bajo valor económico, como los asentamientos informales, pero también a los conjuntos cerrados de alto valor.

Los 24 barrios seleccionados se analizaron según el mapa de pendientes realizado por los autores y las características de las laderas determinadas en la cartografía oficial sobre el ordenamiento territorial (tabla 5). De forma general, se pueden clasificar las laderas como: 1) urbanizadas (sin suelos de protección), 2) perimetrales al casco urbano (limitantes de la expansión urbana y áreas de interés ambiental) y 3) de protección ambiental. El concepto de ladera urbanizada es propuesto por los autores, pues el ordenamiento territorial solo trata explícitamente de las laderas correspondientes a suelos de protección.

Las laderas de protección ambiental presentan características geológicas y geotécnicas de interés como alta pendiente, presencia de agua, evidencia de movimientos antiguos o activos de diferente tipo y antecedentes de inestabilidad con pérdidas humanas y materiales; en consecuencia, no se permite ningún tipo de intervención antrópica en dichas laderas, salvo las enfocadas en garantizar su estabilidad y la preservación del recurso biótico, paisajístico y cultural.

Los barrios Sacatín, Las Colinas, Vivienda Popular, Pío XII, El Nevado y Solferino presentan riesgo alto por deslizamiento, tal como aparece en el plano AU-16-1 del Plan de Ordenamiento Territorial (POT) de 2007. Según los planos consultados, el Centro no ha tenido necesidad de tratamiento geotécnico, y en los barrios La Estrella y San Antonio se han realizado obras específicas de estabilidad, según plano 07-BU-62-1 del POT de 2017. Solo en el barrio San Antonio hay un registro de un proceso erosivo conforme al plano D-2E del POT de 2017.

En el caso del Centro, es necesario reiterar que el riesgo geotécnico del sector y algunas áreas aledañas está asociado a la estabilidad de los rellenos sobre los cuales fueron construidos cubriendo los drenajes naturales y eliminando las laderas y su cobertura natural. Otros barrios, como Villapilar, La Sultana y Palermo (no considerado en el presente estudio), también se construyeron sobre modificaciones similares del terreno (Correa Calle, 2015).

Manizales es una ciudad planificada con diferentes contribuciones, y algunas son producto de la espontaneidad propia de asentamientos informales, lo que ha generado un equilibrio entre unidad y diversidad que brinda características atractivas en términos morfológicos. A pesar de los esfuerzos institucionales por aumentar espacios públicos, aún existen 15 barrios carentes de estos: 20 de Julio, Arenillo, Bella Montaña, Cerros de La Alhambra, Colón, Estrada, Galán, La Argentina, Maltería, Morrogacho, Sacatín, San Antonio, San Ignacio, Sierra Morena y Zona Industrial.

Los barrios de origen público o mixto fueron desarrollados por urbanizaciones, con tramas reticulares principalmente; la práctica planificadora privilegió el uso de la retícula, mientras que los barrios de autogestión fueron desarrollados por agregación de manzanas y viviendas con tramas orgánicas e irregulares, principalmente. La aparición de nuevas tramas, como los cul-de-sac y los conjuntos cerrados, son una respuesta a los cambios que ha tenido la ciudad: la generalización del modo privado de transporte, el aumento de la densidad urbana y el incremento de áreas urbanizadas de uso residencial.

\section{Discusión}

La investigación sobre morfología urbana con sistemas de información geográfica y variables cuantitativas permite diferenciar las formas urbanas a través de métodos objetivos y concisos basados en resultados numéricos (Prieto Medina et al., 2018; Nedovic-Budic et al., 2016; Voltersen et al., 2014). El procesamiento de imágenes
(A) Tabla 5. Barrios seleccionados agrupados según las características de las laderas.

Fuente: elaboración propia (2019).

Nota: elaboración con base en la tabla 1. Laderas de protección ambiental del Plan de Ordenamiento Territoria Componente Urbano y en el Cuadro 2. Laderas perimetrales al casco urbano (Acuerdo Municipal 663 de 2007. Artículo 144 
digitales y los métodos automatizados de cálculo de densidad, la mezcla de usos del suelo y la distribución espacial permiten desarrollar investigaciones interdisciplinarias donde se vinculan áreas del conocimiento como la ecología urbana, la geotecnia y la gestión de riesgos, entre otras. Las contribuciones clave de estos métodos consisten en la inclusión de la vegetación, de las pendientes, del confort térmico y de otras características naturales. Una limitación de este tipo de enfoques morfológicos es la baja resolución de los resultados, porque esta no es adecuada para toda una ciudad y requiere pequeñas unidades de análisis; sin embargo, puede ser una ventaja para visualizar detalles como calles, manzanas y predios. El método desarrollado por los autores, basado en la superposición de tramas, pendientes y caracterización de laderas, permitió entender la ocupación del territorio con su diversidad de formas urbanas. La aplicación de este tipo de métodos requiere disponibilidad de información confiable y depurada; si es posible, de carácter oficial. Es de particular importancia desarrollar bases de datos detalladas sobre eventos (deslizamientos) o características geotécnicas del terreno (rellenos), que son de interés como determinantes del desarrollo de los diferentes tipos de tramas urbanas. Las tramas de tipo culde-sac y conjuntos cerrados son susceptibles de procesos geotécnicos que se desarrollan dentro de espacios privados, lo cual impide la oportuna intervención de recursos públicos antes de que los procesos alcancen dimensiones suficientes para afectar infraestructura de interés general.

Los resultados obtenidos en cuanto a la caracterización de la ciudad según sus tramas urbanas y el mapa de pendientes y laderas proporcionan una base para revisar la gestión urbana a escala de barrio, determinar los lugares potencialmente adecuados para espacios públicos y comprender cómo la forma y las condiciones físicas de la ciudad deben ser consideradas en la configuración de las futuras tramas; de hecho, el resultado de este ejercicio ilustra el potencial del análisis multicriterio sobre sistemas de información geográfica en estudios a pequeña escala, cercanos al análisis puntual, contrario al postulado acerca de su conveniencia en estudios regionales (Chowdhury, Flentje \& Bhattacharya, 2010).

Los estudios sobre caracterización morfológica de ciudades colombianas son escasos, y no se hallaron investigaciones que integraran las formas urbanas con la caracterización de pendientes. Por esto, cobran relevancia las investigaciones interdisciplinarias, pues contribuyen a la comprensión y la gestión de los procesos de desarrollo urbano. Los diferentes enfoques morfológicos concuerdan en que la ciudad se puede leer y analizar a través de sus formas urbanas; lo que cambia son los conceptos, las categorías y las variables por tener en cuenta.

\section{Conclusiones}

La caracterización urbana propuesta en este artículo privilegia la comprensión por unidades o fragmentos urbanos como un ámbito ideal para un análisis, contrario a la concebida desde un plan urbanístico general, que aborda la totalidad de una ciudad. La unidad espacial del barrio es una alternativa para destacar las particularidades de las ciudades.

Los autores consideran relevante el estudio simultáneo de la transformación ambiental del suelo con simulaciones según los proyectos de desarrollos urbanísticos. Este tipo de estudios es subvalorado, y, en consecuencia, se generan problemas ambientales tanto en los desarrollos urbanísticos planificados como en los no planificados. En el caso de Manizales, se plantea la dicotomía entre la intersección de drenajes y laderas, para urbanizar formas reticulares y regulares, o adaptarse al terreno generando formas discontinuas con problemas de conectividad y espacios públicos residuales.

La relación entre la trama y la condición económica es evidente en las formas de crecimiento espontáneo con procesos de autogestión correspondientes a tramas orgánicas, con procesos de autogestión y configuraciones a partir de agregaciones de manzanas y viviendas, mientras que las formas de crecimiento planificado corresponden a procesos de urbanización y están principalmente ligadas a las tramas reticulares. La tendencia a aislar los barrios de altos ingresos en conjuntos cerrados es notoria en las zonas periféricas de la ciudad; además, aumenta los efectos de la segregación socioespacial y de la fragmentación urbana.

La diversidad del paisaje de Manizales se ve reflejada en la variedad de formas urbanas, que van desde una trama de damero de origen hispanoamericano hasta tramas radiales. El damero y los grandes movimientos de tierra asociados se dejaron de emplear desde mediados del siglo $X X$. Las tramas posteriores tratan de adaptarse al terreno existente, lo cual no implica la reducción del riesgo geotécnico que reemplaza la incertidumbre en la estabilidad a largo plazo de grandes rellenos sobre líneas de drenaje, por el corte de laderas naturales susceptibles a la erosión y a la inestabilidad por factores naturales (sismo, Iluvia) y antrópicos. La propuesta del concepto de ladera urbanizada amplía el espectro de opciones de investigación sobre las condiciones actuales o pasadas de la ciudad y la transformación ambiental del territorio.

\section{Agradecimientos}

Se agradece la colaboración de los estudiantes del Semillero de Investigación URBI-SIG, de la Escuela de Arquitectura y Urbanismo de la Universidad Nacional de Colombia sede Manizales. 


\section{Referencias}

Acuerdo Municipal 663 de 2007 (Concejo Municipal de Manizales). Por medio del cual se revisa el Plan de Ordenamiento Territorial de Manizales. (13 de septiembre de 2007).

Acuerdo Municipal 958 de 2017 (Concejo Municipal de Manizales). Por medio del cual se adopta el Plan de Ordenamiento Territorial. Documento Técnico de Soporte. Componente Urbano. (2 de agosto de 2017).

Alcaldía de Manizales. (10 de noviembre de 2019). Shape de barrios, manzanas, predios, espacios públicos, curvas de nivel y áreas de tratamiento geotécnico. Manizales, Caldas, Colombia.

Alexander, C. ([1965] 2009). La ciudad no es un árbol. Ciudades para un futuro más sostenible. Architectural Forum, 122(1), 58-62 (Part I); 122(2),58-62 (Part II).

Recuperado de http://habitat.aq.upm.es/ boletin/n40/acale.es.html

Alexander, C., Ishikawa, S., \& Silverstein, M. et al. (1980). Un lenguaje de patrones. Ciudades. Edificios. Construcciones. Colección Arquitectura/Perspectivas. Editorial Gustavo Gili S.A.

Bellet Sanfeliu, C. (2007, agosto 1). Los espacios residenciales de tipo privativo y la construcción de la nueva ciudad: visiones de privatopía. Revista Electrónica de Geografía y Ciencias Sociales, XI(245 [08]). Recuperado de: http://www.ub.edu/geocrit/sn/sn-24508.htm

Bonilla Sandoval, R. (1999). Tramas viales y morfología urbanística en Cali. Cuadernos CITCE. Serie Investigaciones No. 1. Cali, Colombia: Universidad del Valle.

Capron, G., \& Esquivel Hernández, M. (2016). El enclave urbano, lógica socioespacial de la periferia urbanizada y sus efectos sobre la segregación residencial y la fragmentación urbana. Cuadernos de Geografía: Revista Colombiana de Geografía, 25(2), 125-149. http://dx.doi.org/10.15446/rcdg.v25n2.54720

Chowdhury, R., Flentje, P., \& Bhattacharya, G. (2010). Geothecnical Slope Analysis. The Netherlands: CRC Press/Balkema.

Cifuentes Ruiz, P., \& Londoño Linares, J. (2010). Análisis del crecimiento urbano. Repositorio Institucional de la Universidad Nacional de Colombia. Gestión y Ambiente, 13(1), 53-66. http://www.bdigital.unal.edu.co/27526/1/2538489307-1-PB.pdf

Correa Calle, O. (25, 26 y 27 de mayo de 2015). Investigación Geotécnica, Geología Urbana y Mapa de Rellenos. Simposio Interdisciplinar sobre Adaptación y Gestión Local del Riesgo de Desastres. El Estado del Arte, la práctica de la gestión y la experiencia de Manizales. Manizales: Gestión del Riesgo Manizales - Colombia. Recuperado de http://www.gestiondelriesgomanizales.com/ Documentos/Presentaciones/19_Invest_ Geotecnica_OscarCorrea.pdf

Francel, A. (2017). La superposición de cartografía histórica como método de análisis morfológico y toma de decisiones urbanísticas. Ibagué, Colombia, 1935-2016. URBE. Revista Brasileira de Gestão Urbana, 9(2), 293-313.

doi: http://dx.doi.org/10.1590/21753369.009.002.ao10
Gaviria Ríos, M. (2017). Configuración espacial de la formación urbana regional del Eje Cafetero colombiano. Cuadernos de Geografía: Revista Colombiana de Geografía, $26,155-170$. http://dx.doi.org/10.15446/rcdg.v26n1.56666

Giraldo Mejia, H., \& Mertins, G. (2000). Manizales/ Colombia: Una típica ciudad mediana andina. Espacio y Desarrollo, (12), 143-156. Recuperado de::

http://revistas.pucp.edu.pe/index.php/ espacioydesarrollo/article/view/8093/8387

González-Plazas, J. L. (2009). Estado actual de la periurbanización y el hábitat periurbano en Manizales (Colombia). Cuadernos de Vivienda y Urbanismo, 2(3), 92-123.

Recuperado de https://revistas.javeriana. edu.co/index.php/cvyu/article/view/28104

Hidalgo-Guerrero, A. (2008). El papel de la vivienda en la configuración urbana de las periferias: caso de Tunja-Colombia 19072007. Cuadernos de Vivienda y Urbanismo, 1(1), 12-43. Recupera do de:

https://revistas.javeriana.edu.co/index.php/ cvyu/article/view/5481

Kropf, K. (2017). The Handbook of Urban Morphology. Italia: Wiley.

Ley 388 de 1997 (Congreso de Colombia). Por la cual se modifica la Ley 9 de 1989, y la Ley 2 de 1991 y se dictan otras disposiciones (18 de julio de 1997). Diario Oficial No. 43.091. Recuperado de:

https://www.alcaldiabogota.gov.co/sisjur/ normas/Norma1.jsp?i=339

Márquez Duque, L. F. (2010). Hábitat y planificación urbana: instrumentos para la planificación del hábitat a la escala del barrio: ciudades intermedias - caso Manizales (tesis de Maestría en Hábitat. Universidad Nacional de Colombia, Sede Manizales). Recuperadode

http://bdigital.unal.edu.co/1809/1/ luisfelipemarquezduque.2010.pdf

Munizaga, G. (1992). Diseño urbano. Teoría y método. Santiago, Chile: Universidad Católica de Chile.

Nedovic-Budic, Z., Jan Knaap, G., Shahumyan, H., Williams, B., \& Slaev, A. (2016). Measuring urban form at community scale: Case study of Dublin, Ireland. Cities, 55, 148-164. http://dx.doi.org/10.1016/j.cities.2016.02.014

Ochoa Villa, C. (2009). Cambios en la morfología urbana de Yolombó, un pequeño asentamiento en las montañas de Antioquia, Colombia. Cuadernos de Geografía. Revista Colombiana de Geografía, (18), 143-162. https://doi.org/10.15446/rcdg.n18.13034

Ochoa Botero, M. I., Patiño Zabala, J. C., López Rivera L. F., Arroyave Arrubla, S., Vásquez Muñoz, J. L., \& Rueda Franco, O. A. (2013). Estructura Ecológica Principal de Manizales. Grupo HTM, Alcaldía de Manizales, CORPOCALDAS.

Oliveira, V. (2016). Urban morphology. An introduction to the study of the physical form of cities. Portugal: The Urban Book Series. Springer.
Páez Trujillo, D. (2017). Evolución geohistórica de la morfología urbana de Ambalema, Tolima, Colombia. Revista Perspectiva Geográfica, 22(2), 137-158. https://doi.org/10.19053/01233769.5956

Pardo Rueda, R. (2004). La historia de las guerras. Bogotá, Colombia: Vergara.

Prieto Medina, P., Romero de Ávila Serrano, V., Moyano Enríquez de Salamanca, A., Solís Trapero, E., \& Coronado Tordesillas, J. (2018). Identificación, clasificación y análisis de las formas urbanas en ciudades medias: aplicación a las capitales provinciales de Castilla-La Mancha. Anales de Geografía de la Universidad Complutense, 38(1), 87-112. http://dx.doi.org/10.5209/AGUC.60470

Quantum GIS Development Team. (2017). Quantum GIS Geographic Information System. Open Source Geospatial Foundation Project. Recuperado de: http://qgis.osgeo.org

Rivera Pabón, J. A. (2013). Proceso de urbanización y agentes urbanos en Pereira, Colombia. Tesis Doctoral. Doctorado en Geografía, Planificación Territorial y Gestión Ambiental. Barcelona: Universidad de Barcelona. Recuperado de: http://hdl.handle.net/10803/132907

Salazar Ferro, C. (2017). Comprender para incidir: análisis y proyecto en la ciudad durante la segunda mitad del siglo XX. Colección Construcción de lo público 03. Bogotá, Colombia: Universidad de Los Andes.

Satizábal Villegas, A. E. (2012). Armenia, Pereira y Manizales: Reseña histórica de su desarroIlo urbano durante el siglo XX. Manizales, Colombia: Universidad Nacional de Colombia Sede Manizales. Recuperado de: h t t p : //bdigital.un a I. ed u . co/63239/7/9789587613049.pdf

Smith, G., Alcock, A., Paul, M., Bentley, I., \& McGlynn, S. (1999). Entornos vitales: Hacia un diseño urbano y arquitectónico más humano. Manual práctico. Barcelona: Gustavo Gili S.A.

Solá-Morales, M. (1997). Las formas de crecimiento urbano. Barcelona: Ediciones UPC.

Thadani, D. (2010). The language of towns \& cities. A visual dictionary. New York: Rizzoli.

Velásquez Barrero, L. S. (2010). El BioManizales. Manual de Bioarquitectura y Biourbanismo. Manizales, Colombia: Blanecolor Ltda. Recuperado de: http://www.bdigital.unal.edu.co/5191/

Voltersen, M., Berger, C., Hese, S., \& Schmullius, C. (2014). Object-based land covermapping and comprehensive feature calculation for an automated derivation of urban structure types at block level. Remote Sensing of Environment, 154, 192-201.

http://dx.doi.org/10.1016/j.rse.2014.08.024 


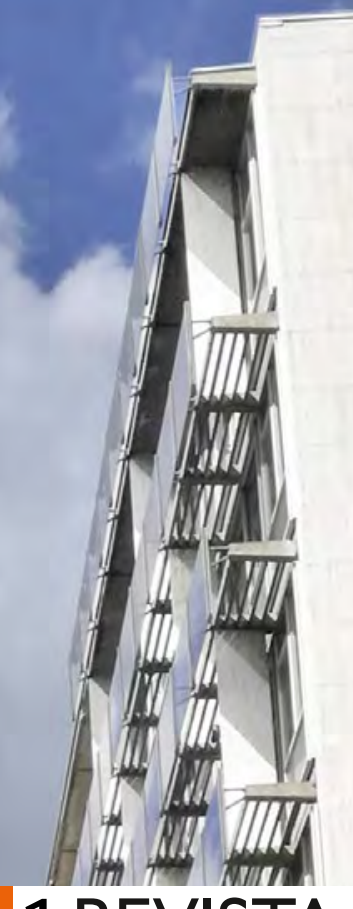

\section{Nro. 1 REVISTA DE ARQUITECTURA}
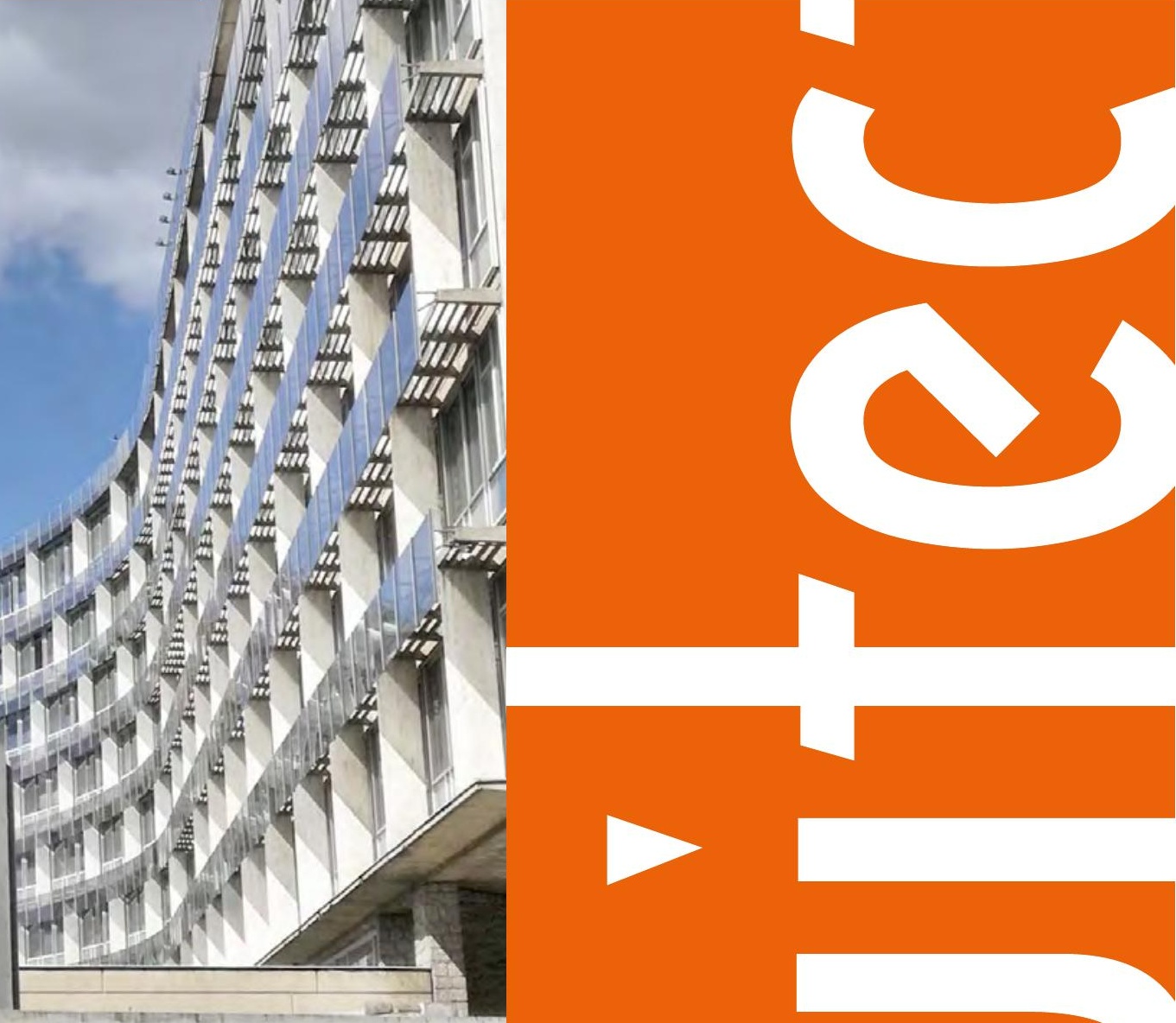

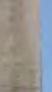

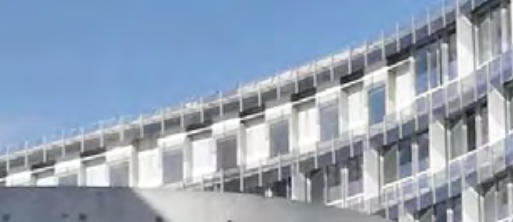

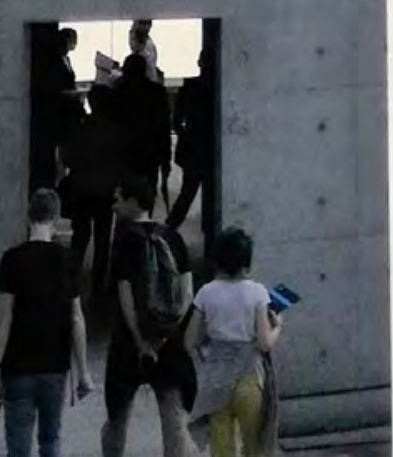

$\Phi$

- Revista de Arquitectura (Bogotá)

- Vol. 22 Nro. 12020 enero-junio

•pp. 1-188•ISSN: 1657-0308•E-ISSN: 2357-626X

- Bogotá, Colombia
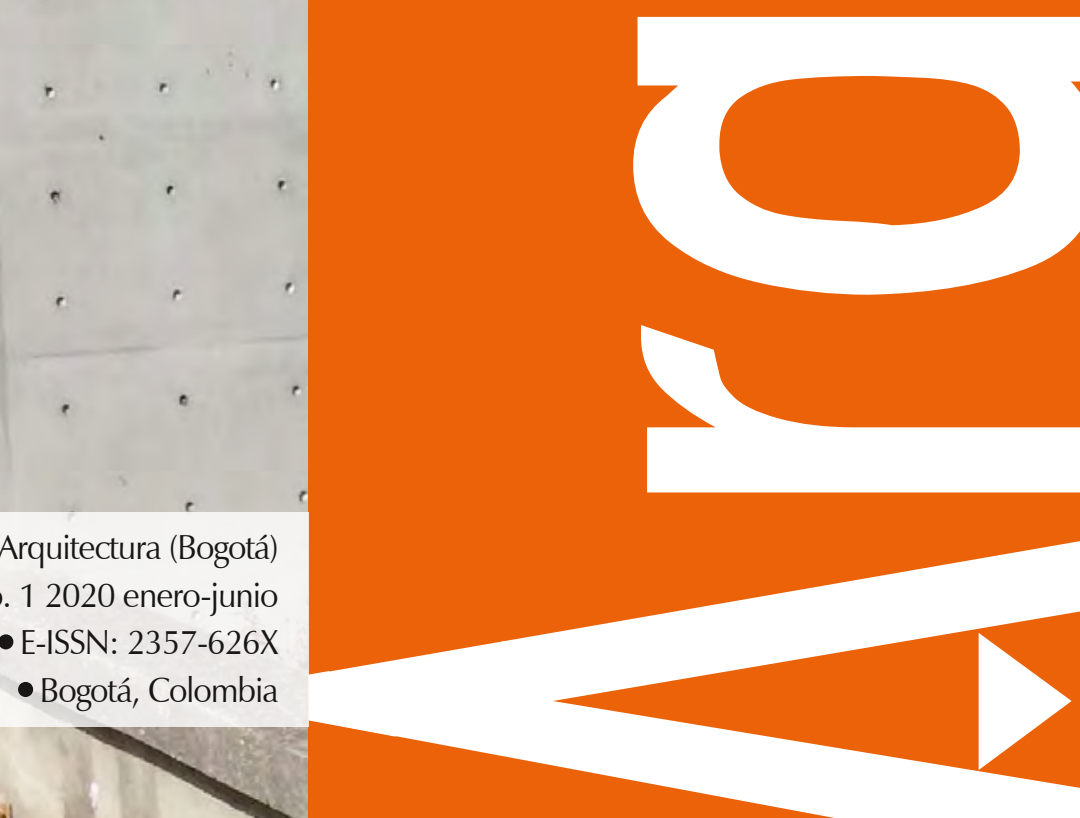


\section{Enfoque y alcance}

La Revista de Arquitectura (Bogotá) ( (ISSN 1657-0308 Impresa y E-ISSN 2357-626X en línea) es una publicación científica seriada de acceso abierto, arbitrada mediante revisión por pares (doble ciego) e indexada, en donde se publican resultados de investigación originales e inéditos.

Está dirigida a la comunidad académica y profesional de las áreas afines a la disciplina. Es editada por la Facultad de Diseño y el Centro de Investigaciones (CIFAR) de la Universidad Católica de Colombia en Bogotá (Colombia).

La principal área científica a la que se adscribe la Revisto de Arquitectura (Bogotá) según la OCDE es:

Gran área: 6. Humanidades

Área: 6.D. Arte

Disciplina: 6D07. Arquitectura y Urbanismo

También se publican artículos de las disciplinas como 2A02, Ingeniería arquitectónica; 5C03, Estudios urbanos (planificación y desarrollo); 6D07, Diseño.

Los objetivos de la Revista de Arquitectura (Bogotá) son:

- Promover la divulgación y difusión del conocimiento generado a nivel local, nacional e internacional

- Conformar un espacio para la construcción de comunidades académicas y la discusión en torno a las secciones definidas.

- Fomentar la diversidad institucional y geográfica de los autores que participan en la publicación.

- Potenciar la discusión de experiencias e intercambios científicos entre investigadores y profesionales.

- Contribuir a la visión integral de la arquitectura, por medio de la concurrencia y articulación de las secciones mediante la publicación de artículos de calidad.

- Publicar artículos originales e inéditos que han pasado por revisión de pares, para asegurar que se cumplen las normas éticas, de calidad, validez científica, editorial e investigativa.

- Fomentar la divulgación de las investigaciones y actividades desarrolladas en la Universidad Católica de Colombia.
Palabras clave de la Revista de Arquitectura (Bogotá): arquitectura, diseño, educación arquitectónica, proyecto y construcción, urbanismo.

Idiomas de publicación: español, inglés, portugués y francés. Título abreviado: Rev. Arquit.

\section{Titulo corto: RevArq}

\section{Políticas de sección}

La revista se estructura en tres secciones correspondientes a las líneas de investigación activas y aprobadas por la institución, y dos complementarias, que presentan dinámicas propias de la Facultad de Diseño y las publicaciones relacionadas con la disciplina.

Cultura y espacio urbano. En esta sección se publican los artículos que se refieren a fenómenos sociales en relación con el espacio urbano, atendiendo aspectos de la historia, el patrimonio cultural y físico, y la estructura formal de las ciudades y el territorio.

Proyecto arquitectónico y urbano. En esta sección se presentan artículos sobre el concepto de proyecto, entendido como elemento que define y orienta las condiciones proyectuales que devienen en los hechos arquitectónicos o urbanos, y la forma como estos se convierten en un proceso de investigación y nuevo de conocimiento. También se presentan proyectos que sean resultados de investigación, los cuales se validan por medio de la ejecución y transformación en obra construida del proceso investigativo. También se contempla la publicación de investigaciones relacionadas con la pedagogía y didáctica de la arquitectura, el urbanismo y el diseño.

Tecnología, medioambiente y sostenibilidad. En esta sección se presentan artículos acerca de sistemas estructurales, materiales y procesos constructivos, medioambiente y gestión, relacionados con los entornos social-cultural, ecológico y económico.

Desde la Facultad. En esta sección se publican artículos generados en la Facultad de Diseño, relacionados con las actividades de docencia, extensión, formación en investigación o internacionalización, las cuales son reflejo de la dinámica y de las actividades realizadas por docentes, estudiantes y egresados; esta sección no puede superar el $20 \%$ del contenido.

Textos. En esta sección se publican reseñas, traducciones y memorias de eventos relacionados con las publicaciones en Arquitectura y Urbanismo.
A Frecuencia de publicación

Desde 1999 y hasta el 2015, la Revista de Arquitectura (Bogotá) publicó un volumen al año, a partir del 2016 se publicarán dos números por año en periodo anticipado, enero-junio y julio-diciembre, pero también maneja la publicación anticipada en línea de los artículos aceptados (versión Post-print del autor).

La Revista de Arquitectura (Bogotá) se divulga mediante versiones digitales (PDF, HTML, EPUB, XML) e impresascon un tiraje de 700 ejemplares, los tiempos de producción de estas versiones dependerán de los cronogramas establecidos por la editorial.

Los tiempos de recepción-revisión-aceptación pueden tardar entre seis y doce meses dependiendo del flujo editorial de cada sección y del proceso de revisión y edición adelantado.

Con el usuario y contraseña asignados, los autores pueden ingresar a la plataforma de gestión editorial y verificar el estado de revisión, edición o publicación del artículo.
A Canje

La Revista de Arquitectura (Bogotá) está interesada en establecer canje con publicaciones académicas, profesionales o científicas del área de Arquitectura y Urbanismo, como medio de reconocimiento y discusión de la producción científica en el campo de acción de la publicación.

\section{Mecanismo}

Para establecer canje por favor descargar, diligenciar y enviar el formato: RevArq FP20 Canjes
Universidad Católica de Colombia (2020, enero-junio). Revista de Arquitectura (Bogotá), 22(I) I-I88. Doi: 10.14718

ISSN: $1657-0308$ E-ISSN: 2357-626X

Especificaciones:

Formato: $34 \times 24 \mathrm{~cm}$

Papel: Mate $115 \mathrm{~g}$

Tintas: Negro y policromía
A Contacto

Dirección postal:

Avenida Caracas No. 46-72

Universidad Católica de Colombia

Bogotá D.C.(Colombia)

Código postal: 111311

Facultad de Diseño Centro de Investigaciones (CIFAR). Sede El Claustro. Bloque "L", 4 piso Diag. 46A No. 15b-10 Editor, Arq. César Eligio-Triana

Teléfonos:

+57 (1) $3277300-3277333$

Ext. $3109 ; 3112$ o 5146

Fax: +57 (1) 2858895
Correo electrónico:

revistadearquitectura@ucatolica.edu.co cifar@ucatolica.edu.co

Página WEB: www.ucatolica.edu.co vínculo Revistas científicas

http://publicaciones.ucatolica.edu.co revistas-cientificas http://editorial.ucatolica.edu.co/ojsucatolica/revistas ucatolica/index.php/RevArq 
